\title{
Competition in the Market for Takeover Advisers
}

\author{
Raymond da Silva Rosa* \\ Philip Lee** \\ Michael Skott*** \\ and \\ Terry Walter****x
}

Senior Lecturer, School of Business, The University of Sydney,

Phone + 61293517093

** Lecturer, School of Business, The University of Sydney, Phone + 61293513067

*** $\quad$ Associate, The Boston Consulting Group, Phone + 61293235600

**** $\quad$ Professor, School of Business, The University of Sydney, Phone + 61293517077

x Corresponding Author: Prof T S Walter, School of Business, Faculty of Economics and Business, The University of Sydney, NSW 2006, Australia, Phone +612 9351 7077, Fax +612 9351 6638, Email t.walter@econ.usyd.edu.au 


\title{
Competition in the Market for Takeover Advisers
}

\begin{abstract}
This paper investigates the attributes of takeovers that motivate bidders to engage advisers, the factors bidders consider when choosing the prestige of advisers and whether advisers that capture greater value for the bidder gain additional market share. The results indicate that advisers are more likely to be chosen in takeovers that are large, hostile, and involve a range of payment methods. Higher ranked advisers are shown to facilitate deal completion. An alternative league table is also created and tested. The results show that advisers who add value to bidders are rewarded with an increase in deal flow in subsequent years.
\end{abstract}

\section{Introduction*}

The Australian market for takeover advisers is large. In 1998 the market value of announced takeover bids was $\$ 41.0 \mathrm{bn}$, of which $\$ 34.0 \mathrm{bn}$ worth of deals had at least one adviser involved. However, there is no legal requirement to use an adviser in a takeover which suggests that the expected value-added by the advisers exceeds their expected fees. The first question is what attributes of a takeover motivate some bidders to hire advisers.

Historically, advisers were kept on retainers by larger firms. However, Bowers and Miller (1990) observe that, in recent times, "investment bankers are acting as independent agents in the marketplace, no longer looking at long term relationships with individual firms", and that the expansion of the takeover market during the late 1980s prompted the move away from "relationship banking". However, the lack of an ongoing contractual commitment between advisers and their clients increased the need for advisers to convey their relative quality in a credible, public way to potential clients.

Advisers can use a variety of signals to convey quality. One very visible signal is the annual takeover adviser league table. The Securities Data Corporation (henceforth SDC) database used to prepare the league table is compiled independently and ranks advisers on the basis of volume of completed takeovers over the previous 12 months. A high ranking is typically interpreted as a sign that the adviser is of high quality. In any event, advisers compete fiercely to be ranked higher. However, whether the league table, as currently compiled, identifies adviser quality is debatable, given that rankings are based on volume of deals completed rather than value-added in a takeover. The second question examined in this paper is what factors do bidders consider when choosing the prestige level of an adviser. In particular, we are interested in whether bidders value wealth creation.

\footnotetext{
* This paper has benefited from comments of David Emanuel (the discussant) and participants at the Third Annual Summer Research School hosted by The Accounting Foundation at the University of Sydney and the School of Accounting at the University of Technology, Sydney in February 2000, the PACAP/FMA Conference, Melbourne in June 2000 and the Asia-Pacific Finance Association Conference, Shanghai, in July 2000. The authors also wish to thank Tig Ihnatko for econometric advice and Emily Rosier for help with data collection.
} 
In theory takeovers should only be undertaken if they have a positive net present value. The literature generally concludes that the greatest returns in takeovers go to target shareholders, and that bidder returns are close to zero or at times negative. A higher quality adviser may be able to ensure bidder shareholders retain a greater proportion of the gains generated by the takeover ${ }^{1}$. If adviser rankings are interpreted as quality rankings, then potentially a key determinant of an increase in market share is the economic rents captured for the bidder. If the league table conveys true quality, then higher ranked advisers should be extracting greater rents for their clients. The third question addressed in this paper investigates whether there an association between adviser ranking on the league table and the economic rents earned by the bidder.

In summary, this paper examines three questions. Firstly, what deal attributes motivate some bidders to engage advisers? Secondly, what factors do bidders consider when choosing the prestige level of an adviser, in particular, do higher ranked advisers capture greater value for their clients? Finally, is capturing greater wealth for the bidder associated with a greater market share? Thus, this paper examines if the current league table conveys adviser quality.

\section{Motivation}

Overcoming agency costs and aligning principal and agent incentives is an important issue in all economic transactions. Although explicit contractual clauses can go a long way towards aligning incentives, contracts are not complete, and future events are uncertain. The principal agent relationship which exists between a takeover adviser (the agent), and a bidder (the principal) is an example of a contract in which the interests of the agent may diverge from the interest of the principal. The bidder should be interested in maximising its wealth, and the takeover adviser in maximising its current and future revenues.

In order to charge higher fees, the adviser must be perceived to offer a superior service. One way to signal quality and superior skill is to be ranked highly on a league table. The prestige conferred by being high on the league table builds up reputational capital, which is used as a marketing tool (Riva (1997)). Since the league table ranks advisers on their completed deals during the past calendar year, there is an incentive for advisers to focus more on deal completion than adding value. Rau (1999) finds support for advisers focusing on deal completion, almost exclusively. Very little support is found for advisers being able to create value for the bidder.

\footnotetext{
${ }^{1}$ If the market for corporate control is perfectly competitive, the target will capture most of the gains associated with a takeover. Accordingly the role of a bidder adviser might be to minimise bidder losses.
} 
This paper aims to shed additional light on Rau's (1999) US results. Since the main aim of a takeover should be to add value to bidder shareholders, it seems economically questionable that deal completion takes precedence over adding value. This paper takes the position that research design issues partially explain Rau's results. These issues are elaborated on in Section IV D.

The league tables that rank takeover advisers use simple rules to generate the rankings. Adding value is not taken into consideration by the league table in its current form. Only completed deals are counted. Further, in cases where there are several advisers engaged in a takeover bid, each adviser to a deal is credited with the full $100 \%$ of the deal value, regardless of the volume of work performed or the risk assumed by the adviser. It is therefore debatable whether the current league table captures adviser quality.

During the period examined in this paper (1989-1998) there were some important differences between the Australian and overseas markets. These include capital gains tax laws (CGT), the composition of the market and the size of the takeovers performed. The more distinctive features of the Australian equities market are briefly discussed below.

CGT laws in place in Australia during 1989-1998 caused more takeovers to be financed by cash than shares, because CGT was applied equally to cash and share consideration i.e., there was no relief in sharefor-share swaps. A target shareholder who accepted cash was certain of his/her ability to pay the CGT, at his/her marginal rate of tax. However, a target shareholder who accepted shares was not certain of his/her wealth, as the value of the consideration offered might decrease with the share price. In $1998,91 \%$ of completed takeovers in Australia were financed by cash (see Ernst \& Young Mergers \& Acquisitions Index (1999)). This is much higher than in the US, where 64\% of takeovers were financed by cash (e.g. Servaes and Zenner (1996) for bids in the period 1981-1992).

US and Australian takeover markets also differ on other attributes e.g. Australia has relatively more resource stocks, and takeovers performed in Australia are considerably smaller. While the industry knowledge advisers need to have is different, the objectives of bidding firms remain as wealth creation through deal completion. Hence, despite the Australian market having different attributes, the findings of this research should remain applicable in other markets.

In summary, we have several motivations in performing this study: First, we hope to shed additional light on the findings of Rau (1999), which seem questionable in efficient markets. Second, we investigate whether bidders are able to assess the quality of advisers by using an existing or alternative league table. Third, we assess whether higher ranked advisers are of higher quality and are thus able to extract greater rents for the bidder. 


\section{Background}

\section{A Introduction}

This Section develops an understanding of takeover advisers, the tasks they perform and the advantages they potentially bring to a takeover. The benefits of using a takeover adviser are balanced against the agency cost incurred when the interests of the adviser diverge from those of the bidder. On the basis of the evidence in the IPO literature (see Beatty and Ritter (1986)) and elsewhere, it is argued that the reputational capital of an adviser reduces the agency cost between the adviser and the bidder. Chemmanur and Fulghieri (1994) argue that investors use the investment bank's past performance to assess credibility, thus a league table is a key marketing tool used by advisers to convey their ability and quality. The Section also discusses the league table; how it is calculated, its perceived importance, the benefits of higher ranking, and its apparent shortcomings.

\section{B Takeover Advisers}

Takeover advisers are financial intermediaries, who help facilitate takeovers. As the relationship between the bidder and adviser is a principal-agent relationship, agency costs are present. Jensen and Meckling (1976) argue that agency costs are incurred when agents (advisers) depart from value-maximizing decisions, and principals (bidders) incur costs to monitor agents and influence their actions.

If an adviser suggests increasing the price offered for the target above the level where all benefits have been eroded, then the bidder's value is likely to be reduced. In this case the better option is to withdraw the bid. However, the adviser's fees are likely to be contingent on deal completion (McLaughlin (1990)), thus the adviser will attempt to complete the deal, even if it destroys some of the bidder's value. This strategy will only work if the adviser does not develop a reputation for closing out deals too early, thereby giving value away to the target. To minimise the risk of overpaying, the bidder incurs monitoring costs to ensure the price suggested by the adviser is reasonable. Agency costs can be reduced if the adviser's reputation capital is at risk. It takes many years to develop a reputation, thus advisers are reluctant to take great risks for fear of damaging their reputational capital.

\section{B.1 The Objectives of the Adviser}

Advisers to bidders can have two objectives: to ensure the deal is completed (deal completion hypothesis, Rau (1999)), or to maximise wealth for the bidder (superior deal hypothesis, Rau (1999) and Bowers and Miller (1990)). These are not necessarily mutually exclusive objectives. Increasing the price offered until no other bidder is willing to enter the market can complete a deal. However, this will reduce the gains (or increase the losses) for the bidder. Alternatively, the bidder can decide on a maximum price. If a competing bidder is willing to pay more than this price, and the bidder pulls out of the deal, bidder 
shareholders will be better off than if the bidder had focused on deal completion. Hence deal completion can be sacrificed in favour of ensuring creation of real value. Nevertheless, it is possible to be the highest bidder and still generate value. Deal completion may overrule value creation if managers become personally involved (Eccles, Lanes and Wilson (1999)). If managers perceive withdrawing an offer as a humiliating loss or if they wish to expand their "corporate empire" at all costs, then it is conceivable that deal completion can overrule value creation. The exception to this is the corporate raiders who "fail" to acquire the target, but earn large "greenmail" profits. The adviser must therefore balance the two objectives, and decide what weight is optimal for each transaction.

Rau (1999) investigates 438 tender offers and 2,683 mergers in the US to establish the determinants of the takeover advisers market share. Rau's sample contains both completed and withdrawn takeovers, and covers the time period 1980 to 1994. Rau tests the superior deal hypothesis and the deal completion hypothesis by regressing post acquisition performance of the bidder on the market share of the adviser. Rau also controls for completion rates, the attitude of the deal, the method of financing and whether the deal is challenged. Rau finds support for the deal completion hypothesis, and little support for the superior deal hypothesis, suggesting advisers are more interested in completing takeovers than generating value for the bidder. This result is seemingly at odds with economic rationality and provides a major reason for this paper's examination of the issue in an Australian setting.

Servaes and Zenner (1996) also find no support for the superior deal hypothesis, but Bowers and Miller (1990) do find some support in that the combined wealth gain to the bidder and the target is higher when a first tier adviser is used. Using a sample of 343 takeovers, Michel, Shaked and Lee (1991) examine the premium paid by bidders, and the returns that accrue to acquirers, as a function of their adviser. They find evidence to suggest the highest ranked adviser under-performed ${ }^{2}$ the sixth ranked adviser $(* * * *$ check this****), which is inconsistent with the superior deal hypothesis. This paper investigates the superior deal hypothesis using the total wealth generated by the takeover, rather than cumulative abnormal returns (CAR) used in the above-mentioned studies. CARs are equally weighted; hence, although the dollar gain to two firms of different size may differ substantially, the CARs may be identical.

\section{B.2 Agency Costs between the Adviser and the Bidder}

Agency costs arise when a bidder employs an adviser. The adviser attempts to complete the deal and earn its fee, while the bidder is interested in adding as much value as possible ${ }^{3}$. McLaughlin (1990) argues that the existing fee structure in the US could lead to greatly increased agency costs, as advisers have the

\footnotetext{
${ }^{2}$ Performance was measured as the share price premium paid by the bidder. A lower premium was considered to be better.

${ }^{3}$ McLaughlin (1990) finds $80 \%$ of fees paid to advisers in the US are contingent upon the deals being completed. As fees are not disclosed in Australia, the impact of fee structure is unknown.
} 
incentive to complete deals irrespective of bidder wealth creation or destruction ${ }^{4}$. McLaughlin's (1990, 1992) papers suggest the method of payment could be altered to reduce agency costs ${ }^{5}$. However, as the market has not attempted to change the advisers' fee structure, there must be other factors that aid in reducing agency costs. McLaughlin argues that placing the advisers' reputational capital at stake is sufficient to reduce agency costs to a level that the bidder finds acceptable.

\section{B.3 Reputational Capital in the IPO Literature}

The concept of reputational capital is well developed in the initial public offering (IPO) literature. The earliest reference to hierarchies and differences in ability comes from Hayes (1971). The newer literature begins with Beatty and Ritter (1986) who use the Akerlof (1970) 'lemons' problem to highlight the need of a bank to have reputational capital to lend credibility to an IPO. Beatty and Ritter find an inverse relationship between reputational capital and IPO underpricing. Later research by Johnson and Miller (1988) also finds support for the hypothesis that more prestigious underwriters underprice IPOs less. An underwriter who consistently is able to price IPOs close to the market value develops a good reputation. Further, the reputational capital of an investment banker can help reduce agency costs, and lend credibility to an IPO.

Working from the Rock (1986) paper, Carter and Manaster (1990) also have results that suggest reputable underwriters work on less risky IPOs. Megginson and Weiss (1991) have similar findings when they examine venture capital financed firms going public. Megginson and Weiss' findings suggest the use of a venture capitalist significantly reduces the cost of going public.

In more recent research, Nanda and Yun (1997) show that the market value of the lead underwriter advising an IPO is directly related to its performance in the IPO. Thus, how the underwriter performs is important. Simply choosing a less risky IPO is not sufficient to ensure the reputational capital of the underwriter is kept intact. Maintaining reputation requires that the underwriter act with skill.

In summary, the IPO literature shows that underwriters with more reputational capital at stake reduce the underpricing risk of the IPOs they advise. Applying this analysis to takeover advisers suggests that advisers who have more reputational capital at stake choose to advise takeovers that will minimise the damage to their reputational capital. Second, if the adviser does not perform well, then the reputational capital of the adviser is diminished. Thus it is in the best long-term interests of the adviser to ensure the objectives of its client are achieved.

\footnotetext{
${ }^{4}$ Rational bidders are of course aware of these incentives.
} 


\section{B.4 Reputational Capital and Takeover Advisers}

The takeover adviser reputational literature is not as well developed as it is in IPOs. Early work in the area revolves around the issue of agency costs and fees. In the US, most payments to advisers occur on successful closure of a deal. That is, the majority of the fees are actually earned upon completion, and the payment of the adviser occurs at the end of the takeover, see McLaughlin (1990). In such cases the adviser is obliged to assume all or most of the non-completion risk, see McLaughlin (1992). A key strength of an adviser is the financial backing it has. If financial backing is slowly eroded through poor performance in takeover negotiations, then reputation will also suffer. Thus non-completion risk can impact on reputational capital. Reputational capital should also depend on the value added to the bidder, keeping in mind that a completed deal can destroy value for the bidding firm.

Servaes and Zenner (1996) examine why a bidder chooses to use an adviser. The sample is relatively small (99 deals with an adviser, and 99 deals without an adviser for bids between 1981-1992). They find an adviser is more likely to be hired when a deal is more complex, the transaction is a takeover, and when the firm has performed takeovers previously.

Due to the great reliance on contingent fee structure in the US, see McLaughlin (1992), it is not surprising that Rau (1999) finds deal completion to be the most important function of an adviser ${ }^{6}$. This is a reflection of a rational decision by the adviser to maximise its fee payoff. Although advisers appear to focus on deal completion, Rau concludes that in mergers this incentive does not necessarily result in value-destruction for the bidder. For tender offers Rau finds that the core aim of the adviser is to ensure the deal is completed. Clearly, it is unlikely that clients are indifferent to adding value. However, it is possible that the ranking method, and return measure used by Rau are inappropriate. After partitioning his sample into "good"7 and "bad" deals, Rau finds that first tier advisers complete the same proportion of "go

other tiers. However, Rau also finds that the return to bidders is higher in tender offers when a first tier adviser is used. It is surprising that the same result does not emerge for mergers.

The fact that Rau (1999) finds few differences between the tiers could be due to the method he uses to rank advisers. The advisers are ranked based on their deal values and number of transactions announced. The frequency with which an adviser falls into a category i.e., 1-5 (bulge), 6-20 (major), and 21-30 (sub-major) indicates whether the firm over the period of 15 years is a bulge (first tier), major (second tier), or sub-

\footnotetext{
${ }^{5}$ McLaughlin (1990, 1992) does not explicitly state different contracting methods, but recognises he is unable to account for all the factors which influence agency costs.

${ }^{6}$ In Australia the Corporations Law does not require fees to be disclosed in the Part A or Part B statements [s. 750]. Only expenses that are considered to be "very material" need be disclosed, and fees paid to advisers are virtually never judged to be "very material", thus no data on adviser fees are available.

7 "Good" deals are those that have a positive abnormal return for the bidder during the announcement period (day -1 to +1$)$.
} 
major (third tier). The classification is based on data over the full period surveyed and so there is no room for advisers to move between tiers. It is evident in Table 4 of Rau (1999) that the second tier advisers appear to catch up to the first tier advisers and pass them during the last two periods (four years). This suggests some of the reported results may mask the dynamics of the takeover adviser market.

\section{Takeover League Tables}

There are several ways in which an adviser may be chosen. The decision to use a particular adviser can be related to previous interaction with an adviser, recommendation from others, or from credible publicly available information. Among credible public information, one of the most important pieces is the takeover adviser league table.

\section{C.1 Calculation of League Tables}

The takeover adviser league table is calculated annually. SDC compiles it from publicly available information. The rankings are based on the market share, as measured by the sum of dollar value of deals completed, achieved by an adviser during the previous calendar year. In order to be included in the league table a deal must conform to the following characteristics.

- The deal must be completed or unconditional during the calendar year;

- The target must be Australian;

- The deal must have had at least one adviser involved.

Each adviser in a deal is given credit for the deal regardless of the role of the adviser, or the size of its contribution. Hence, if two advisers work on the same deal, they will both be credited with the total value of the deal. Although the approach has shortcomings it does remove subjectivity. SDC avoids having to decide exactly how important each adviser's contribution was to the outcome of the takeover. Advisers can accumulate value during a calendar year by working for both bidders and/or targets. The two are weighted equally. The total market is the sum of all takeovers where at least one adviser has been involved, in 1998 this amounts to $\$ \mathrm{~A} 34.046 \mathrm{bn}^{9}$. The value of all the takeovers an adviser has been involved in is divided by the total value of the market. The advisers are then ranked based on their market share. We question the ability of the league table to capture quality and prestige, and suggest (and test) a ranking method based on value created for clients.

\section{C.2 Shortcomings of the League Table}

The calculation of the league table has several potential problems. Firstly, withdrawn takeover offers are ignored, and the level of risk assumed by an adviser is not taken into account. If an adviser wants to move up the league table, then it could attempt a whole range of deals in the hope that enough are completed to increase its ranking on the league table. For this reason one may not be able to compare two advisers based

\footnotetext{
${ }^{8}$ An "experienced good" is where quality can be verified only after purchase (Chemmanur and Fulghieri, 1994).
} 
on their achieved market share e.g. if two advisers have the same volume of deals completed during one calendar year, but one completes all its deals, and the other completes only half. In this case the league table would indicate the two advisers to be of similar quality, when in fact they differ.

Secondly, all advisers in a deal are credited with the full amount of the deal. If set-up costs allow it, there may be an incentive for advisers to perform a small amount of work e.g. $5 \%$ of the deal, and perform a larger number of smaller engagements in large deals. One method by which the volume of work could be assessed would be through the amount of fees paid to each adviser. Unfortunately, adviser fees are not disclosed in Australia.

Thirdly, risk is ignored in the league table. The greater the number of advisers involved in a deal, the more diversified the project risk. Also, the more deals performed by an adviser in a year, the more diversified its risk will be. Particular deals might be more difficult, yet all deals are credited with a dollar value unadjusted for the complexity of the deal and the degree of risk faced by the adviser. Because the league table does not consider complexity and risk, the rankings may not reflect the underlying ability of the advisers.

Fourthly, deals are credited to both target and bidder advisers. If an adviser is hired by a target to defend the company and the takeover is completed, then the target adviser (despite being unable to achieve its client's objectives) is credited with the deal. Conversely, a target adviser who successfully fights off a bidder is not credited with the deal value. This seems particularly strange in terms of the ostensible objectives of the league table.

Finally, SDC also assume that a completed deal adds value to an acquirer. A deal may in fact be value destroying for all shareholders involved, yet be counted to improve the ranking of an adviser on the league table. A bidder may hire an adviser with the intention of performing "greenmail". If the greenmail objective is achieved, then the takeover is abandoned, and the adviser is not credited with the deal value. Thus, situations can easily exist where takeovers counted actually destroy economic value, and takeovers may not be counted where they achieve the objective of the bidder.

It is understandable that the measure developed by SDC is parsimonious, but its shortcomings reduce the usefulness of the league table. As long as all market participants are aware of the measurement shortcomings, then the league tables can still serve as a reasonable benchmark, and a credible marketing tool. However, there are clear deficiencies associated with the use of the league tables as a reflection of quality.

\footnotetext{
${ }^{9}$ In 1998 the top firm was Warburg Dillon Read with $27.6 \%$ of the market with deals worth $\$ 9.397 \mathrm{bn}$.
} 


\section{Hypotheses Development}

\section{A Introduction}

The Section builds on the previous work of Servaes and Zenner (1996) and Rau (1999) to develop six hypotheses. Servaes and Zenner's (1996) research is related to the decision to use an adviser, whereas Rau (1999) deals with adviser choice. The purposes of the hypotheses below are to test the conclusions drawn in the above research, as well as extending the research by considering value created by advisers.

\section{B Use of Adviser Hypotheses}

The decision to use an adviser has most recently been explored by Servaes and Zenner (1996). They tested three hypotheses: the transaction costs hypothesis, the information asymmetry hypothesis, and contracting cost hypotheses. Examining the results in Servaes and Zenner suggests corporate governance variables have no impact on the decision to use an adviser. Based on that observation, the decision has been made to retest the transaction cost and the information asymmetry hypotheses in an Australian setting. The two hypotheses are set out below.

\section{B.1 The Transaction Cost Hypothesis}

The takeover adviser is in the business of advising bidders and targets, and the bidder is not ${ }^{11}$. Thus it is expected that the adviser is more knowledgeable about takeovers and can perform them at lower costs. According to Benston and Smith (1976) the cost savings come from three sources; economies of specialisation, scale economies and reduction in search costs. The knowledge and costs savings can extend to ensuring there are no post-acquisition legal implications i.e., the bidder is not involved in any litigation for reasons related to the way the takeover was performed. Due to their specialisation, takeover advisers are expected to be able to identify takeover targets, value them, and put together a bid at a lower cost than individual firms, see Servaes and Zenner (1996). Hence, advisers are likely to be hired when they can save on transactions costs.

\section{$\mathrm{H}_{1}$ : The greater the transaction costs, the more likely a firm is to use an adviser.}

As in Servaes and Zenner (1996) transaction costs will be proxied by the following range of complexity measures: size of transaction, diversification of the target, and the previous experience of the bidder. In addition the following dummy variables will be used: whether the target and bidder are in the same industry, and if the deal is hostile.

\footnotetext{
${ }^{10}$ The bidder may still have significant previous experience and firm-specific knowledge.

${ }^{11}$ The bidder may still have significant previous experience and firm-specific knowledge.
} 


\section{B.2 The Information Asymmetry Hypothesis}

The decision to use an adviser is likely to be dependent on the degree of information asymmetry that exists between the bidder and the target. Information asymmetry can exist for a number of reasons. The target and the bidder may operate in significantly different industries, the structure of the two firms may be very different; one firm may be listed and the other private. When information asymmetry is great, it is expected that an adviser will be hired to provide credibility to the information disclosed as part of the bid. The adviser may also be able to provide specific information to either the bidder or the target to make them more informed about the takeover. Thus the following hypothesis is posited.

\section{$\mathrm{H}_{2}$ : The greater the information asymmetry, the more likely an adviser is to be used.}

Two of the variables from Servaes and Zenner (1996) are used to proxy information asymmetry: industry relatedness, and the number of industries in which the target operates. The other proxy used is a dummy equal to one if the bidder is listed. If the bidder is listed, then it is expected that an adviser will be hired to reduce the information asymmetry between the shareholders and the managers. The reputational capital of the adviser will make the information more credible.

\section{Adviser Choice Hypothesis}

The IPO and takeover literature contains several hypotheses related to advisers and the type of work performed. Nanda and Yun (1997) examine the correlation between market value of the lead underwriter and the "success" 12 of the transaction it advised. The results show the market value of the lead underwriter is directly related to its performance in the IPO. Given the way the league table is compiled, and the ranking method used by Rau (1999) ${ }^{13}$, it is not surprising to find that the key determinant of adviser market share is deal completion. Adding value to its client was not found to be a significant determinant of market share for the advisers.

\section{C.1 Bargaining Power Hypothesis}

Roll (1986) states "if there were no value at all in takeovers, why would firms make bids in the first place?" There must be something to be gained from a takeover that is unique to a given combination as a "target firm cannot be depicted generally as being 'undervalued' by the stock market" (Jarrell, Brickley and Netter (1987)). Thus, in theory there should be a net gain from a takeover. Assuming a takeover has a positive NPV, a higher quality adviser will generate greater benefit for the client from the bid.

\footnotetext{
${ }^{12}$ Success was measured by the degree of underpricing in the IPO advised, with lower underpricing considered to be more successful.

${ }^{13}$ Ranking was based on frequency of achieving a market share (based on volume) within certain brackets i.e., top 5 was first tier, 6-15 was second tier, and 16- $\infty$ for third tier.
} 
The more prestigious the adviser, the greater is its reputational capital. Reputational capital aids in reducing agency costs. If the adviser has a great deal at stake, then it is less likely to be willing to make opportunistic decisions, thus when bargaining its actions should be more credible relative to an adviser with less reputational capital. Hence, the more credible the adviser, potentially the higher its bargaining powers i.e., higher ranked advisers should be able to use its resources, expertise and bargaining power to "negotiate the acquisition at a more favourable offer for the firm they are representing", see Bowers and Miller (1990). Accordingly, we posit that higher ranked advisers have better bargaining power.

\section{$\mathrm{H}_{3}$ : Prestigious advisers are more likely to complete "good" deals.}

"Good" deals are defined as those where the bidder announcement return is nonnegative. The window over which the return is calculated is $\mathrm{t}-5$ to $\mathrm{t}+5$ days. ${ }^{14}$

\section{Market Share Hypotheses}

The following hypotheses test what is required for an adviser to have a greater market share. The two hypotheses are the superior deal hypothesis, and the deal completion hypothesis (Rau (1999)). The deal completion hypothesis states an adviser will have a higher market share by increasing its completion rate. Rau (1999) finds little support for the superior deal hypothesis, but a significant amount of support for the completion hypothesis.

\section{D.1 Superior Deal Hypothesis}

There are several ways of defining a superior deal. Rau (1999) defined a “

bidder earns a positive short run abnormal return. If bidders want to generate wealth, then it is expected that advisers who can aid in completing "good" deals will be rewarded with an increased deal flow. Although abnormal returns can aid in identifying "good" deals, the use of equal weights places too much emphasis on small deals. We incorporate the size of a bid in our analysis by aggregating the wealth of all the takeovers an adviser participates in over one year to indicate if the adviser assisted in creating wealth for bidders' shareholders. Wealth will be measured both as an aggregated dollar amount, and as a standardised measure. The measure is standardised by dividing the wealth gain to the bidder by deal value. Whether this measure is superior relative to returns will be indicated by the hypothesis below.

\section{$\mathrm{H}_{4}$ : The greater the wealth created for bidder shareholders, the higher the rank of the adviser.}

The final measure of the superior deal hypothesis relates to the division of wealth generated by the adviser. A higher quality bidder adviser will negotiate a deal in which the bidder retains a larger proportion of the

\footnotetext{
${ }^{14}$ Several alternative return windows were used (i.e., -10 to $+10,-2$ to +2 and -1 to +1 ) and produced similar results.
} 
wealth created. The measure is standardised by dividing the wealth gain to the bidder by the absolute value of total wealth created. If the market rewards this, then the adviser will receive greater deal flow, and subsequently move up the league table.

\section{$H_{5}$ : The greater the amount of wealth created in the deal retained by the bidder, the higher the rank of the adviser in the league tables.}

Despite Rau (1999) finding little support for the superior deal hypothesis, it is expected that by examining wealth creation (rather than returns) some support for the hypothesis may be found.

\section{D.2 Deal Completion Hypothesis}

The deal completion hypothesis argues that for an adviser to increase its market share, correct valuation of a deal for the client is secondary to actually completing the deal. Managers may be fixated on completing a deal rather than ensuring shareholders benefit from the takeover. Although Eccles et al. (1999) discuss the range of control mechanism in place when a takeover occurs, they do admit that managers sometimes "overlook the numbers". They argue that successful managers are ambitious people who do not like to lose, hence when a deal becomes too expensive managers fixate on winning the "contest" rather than ensuring value is added. This is especially the case if the manager will personally benefit from the takeover e.g., larger salary and bonus from managing a larger firm. It is expected that the more prestigious advisers will provide a "no questions asked" type service for its client the bidder i.e., completion rate is likely to be higher the greater the reputational capital of the adviser. Further, only completed takeovers are counted in the current league tables. Thus, higher ranked advisers should have a higher completion rate. Hence, the hypothesis is:

\section{$H_{6}$ : The greater the proportion of deals completed, the higher the rank of the adviser.}

\section{E Summary}

The six hypotheses posited above relate to the three models discussed in the next Section. The transactions cost $\left(\mathrm{H}_{1}\right)$ and information asymmetry $\left(\mathrm{H}_{2}\right)$ hypotheses relate to the adviser used model. The bargaining power hypothesis $\left(\mathrm{H}_{3}\right)$ relates to the adviser choice model. The superior deal hypotheses $\left(\mathrm{H}_{4}\right.$ and $\left.\mathrm{H}_{5}\right)$ suggest the creation of bidder wealth, and higher ranked advisers achieve the retention of a larger proportion of the wealth. The deal completion hypothesis $\left(\mathrm{H}_{6}\right)$ conjectures that the deal completion rate is important in determining the ranking of an adviser. 


\section{Data and Method}

\section{A Introduction}

This Section describes the four data sources, and discusses the three models used to test the six hypotheses developed in Section III. The four data sources are: SDC Platinum, ASX Journal, the Core Research Database, and FT Extel. The three models are: the adviser used model, the adviser choice model and the market share model. The adviser used model and the adviser choice model are based on a takeover-bytakeover analysis, whereas the market share model is based on annualised data. The variables for all three models are discussed individually with a priori expected signs for the coefficients.

\section{B Data}

The data come from four sources, the SDC Platinum database, the Core Research database (CRD), ASX Journals, and FT Extel. The time frame is 1989 to 1998, and contains all attempted takeovers where the bidder is Australian. The bidder has to be Australian; otherwise the price data necessary to test $\mathrm{H}_{3}$ (bargaining power hypothesis), $\mathrm{H}_{4}$ and $\mathrm{H}_{5}$ (superior deal hypotheses) are not available from the CRD.

In order to be included in the sample the takeover had to be announced between 1 January 1989 and 31 December 1998. This identified a total of 4,172 takeovers. All rumored bids were removed leaving 2,610 takeovers. A minimum transaction size of $\$ 500,000$ was selected, so as to ensure that only economically significant takeovers are included. This reduced the sample to 1,326 takeovers. The next restriction imposed on the data was that the bidder must have intended to hold at least $20 \%$ of shares in the target after the takeover. The $20 \%$ minimum was set to ensure deals involve material control transactions ${ }^{15}$. Imposing this restriction results in a sample of 865 takeovers.

The final restriction was to only include public, private and subsidiary firms. This omitted government firms, joint ventures and several firms where the status was unknown. Government firms and joint ventures are omitted because their management does not have to respond to the same commercial incentives as non-governmental firms. Further, price data are not available for any of these types of firms. The final sample contains 801 attempted takeovers.

\section{B.1 SDC Platinum}

The SDC Platinum database was selected, as it appeared to be the most reliable and complete source of takeover data available in Australia. SDC Platinum has been used in a number of recent takeover papers e.g. Rau (1999), and Rau and Vermaelen (1998). Further, the fact that merchant banks themselves use

\footnotetext{
${ }^{15}$ Section $615(7)$ of the Corporations Law outlines $20 \%$ as the minimum percentage at which a person is able to potentially control the affairs of the company.
} 
SDC Platinum to derive information also increases the credibility of the database as a source of reliable data for this study. These factors enhance the external validity of the experiment.

Data availability constraints determined the time frame over which adviser performance is reviewed (1989-1998). Prior to 1989, Australian data compiled by SDC are not sufficiently detailed or comprehensive. The finishing date of 31 December 1998 was selected to make the sample as current as possible, and to minimize the number of deals still pending.

\section{B.2 ASX Journal}

ASX Journals were used to collect the number of shares outstanding one month prior to the takeover. They were also used to identify which firms were listed, and the total assets of each listed firm in the sample ${ }^{16}$.

\section{B.3 Core Research Data}

CRD supplied day end share prices for each of the listed firms in the sample. The data were used to calculate the short run abnormal returns. The Securities Industry Research Centre of Asia-Pacific (SIRCA) compiles the data contained in the CRD. The database contains end of day trading prices, volume, and dilution factors for all securities listed on ASX.

\section{B.4 FT Extel}

FT Extel supplied the all ordinaries accumulation index values for the full time period. The all ordinaries accumulation index was used to approximate the market. The index represents $93 \%$ of value and $94 \%$ of turnover on ASX (see ASX Fact Book (1998)). The all ordinaries accumulation index differentiates itself from the all ordinaries index as dividends are notionally reinvested on the ex dividend date. Hence the all ordinaries accumulation index approximates a buy-and-hold strategy with 100\% dividend reinvestment.

\section{Adviser Used Model}

There are no legal requirements to use an adviser in a takeover. A bidder can write its own takeover documents and submit them to ASX, the ASIC and the target. There are suggestions from Servaes and Zenner (1996) that the decision to use an adviser depends on the complexity of the deal, the diversification of the target, and the amount of previous experience the bidder has. The following logit model sets out to test $\mathrm{H}_{1}$ (transaction cost hypothesis) and $\mathrm{H}_{2}$ (information asymmetry hypothesis). The model is extensively based on that contained in Servaes and Zenner (1996).

\footnotetext{
${ }^{16}$ Shares Magazine replaced ASX Journal in December 1996; hence between December 1996 and December 1998 Shares Magazine provided the required information.
} 


\section{Adviser Used $=\alpha_{0}+\beta_{1}$ Attitude $+\beta_{2} \operatorname{Cash}+\beta_{3} \log ($ Transaction Size $)+\beta_{4} \log ($ Previous Acquisitions $)$ $+\beta_{5}$ Related Industry $+\beta_{6} \log (\#$ Target SICs $)+\beta_{7}$ Market Reaction $+\beta_{8}$ Bidder}

\section{Listed $+\varepsilon$}

Adviser Used is a dummy variable equal to one if the bidder uses an adviser, and zero otherwise. A positive coefficient on any independent variable means the probability of using an adviser is higher when the variable increases.

Attitude is a dummy variable equal to one if the acquisition is hostile, and zero otherwise. In a hostile takeover the bidder needs to avoid the target's takeover defenses, convince the board and shareholders that the price is appropriate, and that the deal will create value. If a deal is hostile, then an adviser can assist by reducing the transaction cost through superior bargaining skills and previous experience. Conversely, an adviser may be able to direct bidders to targets that are more likely to be receptive ${ }^{17}$. Thus a weak positive coefficient is expected for Attitude. A significant positive coefficient will provide support for $\mathrm{H}_{1}$ (transaction cost hypothesis).

Cash is a dummy variable equal to one if cash is the sole means of payment, and zero otherwise. The more complicated the method of payment is, the less likely the target shareholder is to feel comfortable with the amount of wealth being offered. Also, the more complicated the method of payment the more expertise is needed from an adviser to be able to lend credibility to the offer. Hence, if non-cash compensation is used to acquire the target it is more likely that an adviser will be needed to structure the deal, and lend credibility to it. Thus, the coefficient is expected to be negative. A negative coefficient supports $\mathrm{H}_{1}$ (transaction cost hypothesis).

Log (Transaction Size), where Log stands for the natural log, and transaction size is taken to be the price paid for the target net of debt. As the model used is a logit, the logarithm of all continuous dependent variables is used, see Maddala (1992). With a larger deal there may be a greater need for financing, and it is likely that an adviser is hired. Size can also be considered to be a complexity proxy. However, larger firms should have more resources to resist a takeover bid. Thus, the larger the transaction size, the more likely an adviser is to be hired i.e., a positive relationship is expected. Servaes and Zenner (1996) conclude that deal size is a key determinant when deciding to use an adviser. A positive coefficient will support $\mathrm{H}_{1}$ (transaction cost hypothesis).

\footnotetext{
${ }^{17}$ Unfortunately we are unable to observe this process as SDC only records the outcome, and not the initial decision as to whether to make a hostile takeover or choose a friendly target.
} 
Log (Previous Acquisitions) is the number of previous acquisitions performed by a given company, as at the date of announcement ${ }^{18}$. Whether the deal is successful is potentially a product of whether or not an adviser was used ${ }^{19}$. The range of values for this variable is zero to 16 . The log is taken ${ }^{20}$, as the incremental experience gained by performing one extra takeover is not expected to be linear. The number of previous acquisitions is taken to be a proxy for experience. The more experience a bidder has, the less need it has for an adviser, thus the coefficient is expected to be negative.

Related Industry is a dummy variable equal to one if the 3-digit primary SIC code is the same for both the target and the bidder, and zero otherwise. If the two firms operate in the same industry, then information asymmetries and the difficulties associated with integration are significantly reduced. In such cases, the services of an adviser are less likely to be utilised, hence the coefficient is expected to be negative. A significant negative coefficient will support both $\mathrm{H}_{1}$ (transaction cost hypothesis) and $\mathrm{H}_{2}$ (information asymmetry hypothesis).

Log (\# Target SICs) is a complexity measure and is defined as the number of industries in which the target operates. As complexity increases so too does the work needed to accurately assess the impact of the takeover. The integration process between the target and the bidder is also likely to be more complex, and require greater expertise. Thus, the greater the number of industries the target operates in, the more likely an adviser is to be used i.e., a positive relationship.

Market Reaction is a dummy equal to one if the short run abnormal return is non-negative, and zero if the return is negative. A high quality adviser should, through their expertise and easy access to capital, be able to ensure the deal creates value. On the other hand, if the deal is attempted without the use of an adviser, then the bidder may not be able to identify the synergies correctly, thus valuing the target incorrectly and potentially paying too much (or offering too little). Hence, contrary to Servaes and Zenner (1996), a positive coefficient is expected i.e., a positive return is expected to be associated with deals performed with advisers.

\footnotetext{
18 This number was calculated by downloading all takeover attempts contained in the Australian Mergers and Acquisitions database in SDC Platinum. This database covers the period from 1984 to current. The bidding firms were first ranked alphabetically, and then ranked by announcement date. This was repeated for all bidders contained in the SDC database. Deals were included independent of their outcome; this is to ensure all attempted takeovers are included. This is important, as the greatest amount of work initially is to price the offer correctly and sell it to the target. It is also in the initial stages where the decision to use an adviser is made.

19 A weakness of this variable is that the calculation of takeover numbers does not take into account organisational changes i.e., two firms merge and form a completely new company trading under a different name.

${ }^{20}$ If the bidder had no previous experience, then Log (Previous Acquisitions) is set to zero. For the bidders with experience, 1 is added to the logged value. Otherwise, bidders with no experience and bidders who had performed one takeover would have the same value $(0)$.
} 
Bidder Listed is a dummy variable equal to one if the bidder is listed on ASX, and zero otherwise. This dummy is included to account for the amount of reputation at stake for the bidder. If an adviser is hired, the reputational capital at stake of the bidder is reduced as the adviser assumes most of the completion risk (McLaughlin (1992)). Also, the adviser should be able to reduce the information asymmetry between the bidder and its shareholders. Hence, if the bidder is listed, then the use of an adviser is more likely, and thus the coefficient is expected to be positive. A positive coefficient will support $\mathrm{H}_{2}$ (information asymmetry hypothesis).

The adviser used model (1) is run on the entire sample of 801 takeovers.

\section{Ranking the Advisers}

For each IPO in the US there is a "tombstone" advertisement, that highlights the particulars of the issue, and lists the various financial intermediaries involved. The order of appearance on the "tombstone" indicates the rank of the advisers in an IPO. This has been the basis for a ranking method developed by Carter and Manaster (1990) and extended by Johnson and Miller (1988) and Megginson and Weiss $(1991)^{21}$. In the takeover literature advisers have been grouped into three categories ${ }^{22}$, first, second and third tier advisers ${ }^{23}$, where first tier advisers have the greatest amount of reputational capital.

Two methods are used to rank advisers, the "look-back" method and the "cumulative ex-

Rau (1999) groups advisers on the basis of the number of times an adviser is ranked amongst the top five in the league table (first tier), the next 15 (second tier) or lower (third tier). The overall ranking assigned to an adviser is based on the frequency with which it is in the top five, the next ten, or the rest during the 15 years which Rau's sample covers. The advisers were only ranked once, which means Rau assumes the ranking of an adviser is permanent. Servaes and Zenner (1996) also keep their rankings constant during their entire sample period. This means the ranking is performed ex post, with information the market did not have at the time most takeovers were performed. However, the nature of the banking industry is such that most are competing to be at the top of the table. Maher and Cooper (1996) describe the change in the "bulge bracket" and refer to the "five contenders to the new bulge bracket". This suggests that over the long run, the ranking of advisers can and does change, hence it is important to have a flexible ranking method that allows for movement between tiers.

\footnotetext{
${ }^{21}$ Earlier models by Logue (1973), and Beatty and Ritter (1986) have been discarded in favour of the Carter and Manaster (1990) method.

${ }^{22}$ The earliest reference where banks are categorised into brackets comes from Hayes (1971).

${ }^{23}$ The literature also terms these Bulge-bracket, Major-bracket, and Sub-Major bracket [see Rau (1999)].
} 


\section{D.1 Look-Back Method}

This paper uses a similar ranking method, but avoids Rau's ex-post ranking complication. The market share of advisers is based on a slightly modified league table. Basing the rankings in each year on the takeover announcement date, not on the year of takeover completion, modifies the league table. This is done to ensure both successful and unsuccessful takeovers are included.

The nature of the data is such that market share will appear to vary significantly i.e., there may be years where the market share for an adviser is substantial, then the adviser will disappear from the table for a few years. To overcome the problem of advisers not featuring in the rankings table despite having a high reputation due to their deals in earlier years, a smoothing approach has been adopted. In addition to the one-year rankings, the league tables have been aggregated over rolling two- and three-year periods.

For each year of each look-back period, the advisers are ranked based on their market share. Following Bowers and Miller (1990), Servaes and Zenner (1996), and Rau (1999), the top five ranked advisers were deemed to be first tier, the next ten are second tier, and the remaining advisers are taken to be third tier.

\section{D.2 Cumulative Ex-Ante Ranking}

Using the "look-back" ranking the top five ranked advisers are given a score of three, the next ten are given a score of two, and the remaining advisers receive a one. The division of the tiers is based on Bowers and Miller (1990), Servaes and Zenner (1996), and Rau (1999). An adviser is only ranked if it is considered to be active. All advisers are assumed to be inactive at the beginning of the data set (1989), once the adviser has participated in a deal it is considered active. The point allocation process is repeated for all active firms during the period 1989 to 1998. Instead of calculating an overall ranking at the end of the period, the rankings are calculated cumulatively during the period. This allows movement between the tiers, and makes the ranking process more dynamic and realistic. The measure does not punish advisers if they are new, but penalises those advisers at the fringe who perform deals at irregular intervals. Advisers who drop out of the market completely will slowly have their score approach the minimum of one. The aggregation builds into the model some degree of memory by the market.

\section{E Adviser Choice Model}

Having decided to use an adviser, the bidder needs to decide on the prestige level of the adviser. This choice is modelled via a multi-logit regression. The model is based on Servaes and Zenner (1996), and carries over a range of variables from the above Adviser Used Model. The model tests $\mathrm{H}_{3}$ (bargaining power hypothesis). The sample for this model contains only takeovers where the bidder used an adviser. This limits the sample to 247 takeovers. The model is as set out below: 


\section{Tier $=\alpha+\beta_{1}$ Attitude $+\beta_{2}$ Cash Dummy $+\beta_{3} \log ($ Deal Size $)+\beta_{4} \log ($ Previous Acq. $)+\beta_{5} \log (\#$ Target SIC Codes) $+\beta_{6}$ Market Reaction $+\beta_{7}$ Relative Size $+\beta_{8}$ Sign. Bidder $+\varepsilon$

Where Tier is equal to three if the adviser involved is third tier; two if the adviser is second tier; and one if the adviser is first tier. The way the advisers are labeled in the equation means a negative coefficient on the independent variable will be associated with an increased probability of using a higher ranked adviser. In cases where there are multiple advisers, the adviser with the highest tier is chosen to represent prestige level of all advisers. This is consistent with Rau (1999), and Servaes and Zenner (1996). The model is run using the three look-back measures, and the ex-ante cumulative ranking method.

The Attitude dummy is equal to one if SDC considers the takeover to be hostile, and zero otherwise. A hostile takeover has greater risk of not succeeding as the target uses all means necessary to combat it. Hostile takeovers are more risky as their success is by no means guaranteed. As discussed in Section II B.3 the more prestigious advisers have skills to complete complex deals considered too risky by less prestigious advisers. The coefficient is therefore expected to be negative

Travlos (1987), Martin (1996) and Chang (1998) highlight the importance of controlling for the method of payment. The Cash dummy variable is used to capture the method of financing used. It is equal to one if the bidder pays for the target using cash only, and zero otherwise. Unlike the US and UK, Australia had no CGT rollover relief for shareholders accepting share bids. An adviser could use its experience and knowledge to more accurately assess the relative impact of the CGT, thereby making the offer more attractive to the target's shareholders. Most advisers should have reasonable access to the funding sources necessary to complete the acquisition The non-standard bids which use several methods of financing, are more difficult to assess, thus more prestigious advisers should be used to assess and structure the deal. Therefore a positive relationship is expected.

The Log (Transaction Size) variable is the log of the total value of the deal. It is intended to control for any systematic influence due to transaction size, see Carter, Dark and Singh (1998). The larger the deal, the more likely a top tier adviser will want to perform it. A large deal will help ensure a placing in the top ranks. Thus a negative relationship is expected.

The Log (Previous Acq.) is calculated as discussed in Section IV C. The variable is a measure of experience of the bidder. The greater the number of acquisitions performed, the more knowledgeable the bidder becomes. The more knowledge a bidder has, the more specific a task an adviser will be hired for. Experts generally work in niche areas and do not generate the same volume of work as the large mainstream advisers do. Therefore experts will be ranked lower, thus a positive relationship is expected. 
Log (\# Target SICS) is discussed above in the advised used model. The greater the number of SIC codes the target firm has, the more complex the transaction is expected to be. As first tier advisers are expected to have more expertise, and a greater wealth of resources to draw on, then a first tier adviser is more likely to perform more complex takeovers, hence a negative coefficient is expected.

Market Reaction is the short run abnormal bidder return. If the assumption is made that on average the deals which advisers are required to perform are those where credibility is required, then it is expected that the more prestigious the adviser the greater the return will be. Thus the coefficient is expected to be negative. If this variable is negative, then it will support $\mathrm{H}_{3}$ (bargaining power hypothesis).

The time window used to assess the market's reaction is -5 to +5 days, where 0 is the day the deal is announced. By using a short-term window the event can be isolated, and by performing a cross sectional regression, the experiment should be able to reduce the amount of noise in the returns. A potential problem with this variable is that the market reaction is an ex post measure used to proxy for an ex ante decision input $^{24}$.

The Relative Size difference between the bidder in deal $i$ using adviser $j$ and the target in deal $i$ can have an impact on the decision to use a certain tier of adviser. If the bidder is smaller than the target, then it requires an adviser with more credibility. The credibility of the adviser will aid in convincing the target to sell its shares to the bidder. Hence a negative relationship is anticipated. If the variable is greater than one the target is bigger and it is expected the bidder will use an adviser, and vice versa.

Sign. Bidder is a dummy variable equal to one if the bidder, prior to the takeover, owned five percent or more of the target's shares, and zero otherwise ${ }^{25}$. Bidders with a substantial shareholding have lower information asymmetry. Therefore, bidders who are not substantial shareholders are more likely to hire a prestigious adviser. Thus, a negative coefficient is expected.

\section{F Market Share Model}

Knowing what makes an adviser move up or down a league table can be very valuable, as it highlights the attributes in advisers that attract bidders. If the league table is intended to rank advisers based on quality levels, then this model also tests the league table. Michel, Shaked and Lee (1991) found an inverse

\footnotetext{
${ }^{24}$ Unfortunately revision dates are not disclosed in SDC; hence the number of revisions made, or the return to the target from the revisions, cannot be estimated.

25 A substantial shareholding is defined in the Corporations Law to be any person who is entitled to not less than five percent of voting shares. Once the five percent threshold is reached, the substantial shareholder must give notice within two business days of their acquisition.
} 
relationship between the prestige of the adviser and its performance. (****Check****). If similar results are found, it may reflect that the league table is not a good basis for ranking advisers into tiers.

Unlike the models above which were based on individual takeovers, the cross-sectional model set out below uses annualised data. The data are annualised around each adviser for the period of one year. The independent variables are therefore aggregates of the deals performed during the year. The model is based on previous research as well as intuition regarding what the market sees as being valuable in a takeover adviser. The model should help unlock how an adviser develops and retains its reputational capital (rank), and assist in testing hypotheses $\mathrm{H}_{4}, \mathrm{H}_{5}$, (superior deal hypotheses) and $\mathrm{H}_{6}$ (deal completion hypothesis).

\section{Market Share $=\alpha_{0}+\beta_{0}$ Ability to Complete $+\beta_{1}$ Last Year's Market Share $+\beta_{2}$ Accumulated Wealth Gain $+\beta_{3}$ Merger/Tender $+\beta_{4}$ Proportion of Acquisitions $+\beta_{5}$ Average Deal Size + $\beta_{6}$ Time to Complete $+\beta_{7}$ Attitude $+\beta_{8}$ SIC Compatibility $+\varepsilon$

The dependent variable Market Share is similar to that used in Rau (1999). It is the market share achieved during the year.

An adviser's Ability to Complete a deal may be a key selling point, especially if the service sold by the adviser is a "no questions asked" type agreement. It also measures the ability of an adviser to apply its skills. It is calculated as the proportion of successfully completed deals to total deals attempted.

The deals completed and attempted by adviser $j$ are measured over the period of one calendar year. Rau (1999) found that first tier advisers complete more tender offers, but in mergers the third tier advisers outperform first tier advisers. If this variable is positive and significant then it supports the deal completion hypothesis, as more prestigious advisers will complete more deals. Thus a positive coefficient supports $\mathrm{H}_{6}$ (deal completion hypothesis).

Last Year's Market Share is included to determine if the base an adviser built the previous year helped generate business the following year. It is an important variable as it controls for the differences in starting points for the year i.e., a $2 \%$ increase in market share has different implications for an adviser that had a $4 \%$ market share compared to one that had a $10 \%$ market share. It is expected that last year's market share will help generate deals for the adviser the following year. As in Rau (1999), we expect a positive relationship.

Accumulated Wealth Gain is calculated three ways: once as a raw wealth gain, and twice after different methods of standardisation. The variable assesses the wealth adviser $j$ has assisted in generating during the 
calendar year, as in Bowers and Miller (1990). Accumulated Wealth Gain is calculated as the increase in bidder market value (adjusted for the market index) in the period from the day of announcement until the day the deal is withdrawn or completed. This is calculated for all listed bidding firms advised by adviser $j$ during one calendar year.

Presuming that first tier advisers want to protect reputational capital, these advisers need not only to complete the greatest number of deals, but also to perform deals that show their quality. The greater skill, expertise and choice of deals should ensure the first tier advisers are able to generate greater wealth than second and third tier advisers can. Thus, the coefficient is expected to be positive. This would support Bowers and Miller (1990) who find the mean abnormal dollar returns and holding period returns are significantly greater in acquisitions when a prestigious adviser is employed. The wealth measure is standardised in two ways. The first is to divide the bidder wealth gain by the deal value, and the second is to divide it by the total wealth created. If the wealth gain is positive then it supports $\mathrm{H}_{4}$ and $\mathrm{H}_{5}$ (superior deal hypothesis).

In Australia, the SDC database does not distinguish between mergers and tenders, but does indicate if the deal is either a merger or a tender, as opposed to an acquisition of assets. Therefore, the Merger/Tender ratio is calculated by dividing the number of mergers and/or tenders performed during the calendar year by the total number of deals performed. It is expected that sales of assets require a different skill set, and a greater client base to find an appropriate buyer i.e., higher ranked advisers are expected to have the expertise required to perform the sale of assets. Thus, less prestigious advisers will perform more merger and tender offers; therefore the coefficient is expected to be positive.

In the US, target advisers are on average paid 30\% more than advisers acting for the bidder, see McLaughlin (1990). For that reason some advisers may choose to act mainly for targets. The Proportion of Acquisitions variable measures the number of deals adviser $j$ performs as an adviser for bidding firms as a proportion of the total number of deals. Acting for the target takes less time from an adviser's perspective as the target hires its adviser after the bidder does. Thus advisers who act for more targets can perform more deals in a year. Therefore a positive coefficient is expected.

The Average Deal Size is included to control for any systematic differences in the size of deals performed by advisers. It is also included to determine if first tier advisers have their market position simply from performing large deals. If first tier advisers perform larger deals, then the coefficient should be positive.

The Time to Complete variable measures the average time (in days) taken to complete the takeovers (announcement date until withdrawal or acceptance of offer) for an adviser in a given year. This is a 
complexity measure. The longer a deal takes to complete the more complex it is. The expected sign of the coefficient is unknown as a positive coefficient may indicate a deal is complex, and that first tier advisers are the ones who perform the deals. Alternatively, a negative coefficient may mean the more prestigious advisers are better at dealing with complex takeovers and complete them more swiftly.

The Attitude of a deal may be an important determinant of the prestige level of adviser chosen. The annualised variable is calculated as the number of hostile deals divided by the total number of deals. Hostile takeovers have greater risk of not succeeding. Thus, to reduce the time and cost of completing a hostile takeover, the experience and resources available to more prestigious adviser is important. This is opposite to what Servaes and Zenner (1996) expected. They expect more prestigious advisers will avoid hostile takeovers as the risk of jeopardising the adviser's reputational capital. However, Loughran and Vijh (1997) find no evidence that a particular category of bank is overwhelmingly used when the acquisition is hostile. Thus a positive coefficient is expected.

The last complexity measure used is the SIC Compatibility ratio. The ratio also proxies for the amount of information asymmetry that exists between the bidder and the target. The dummy variable is set to one if the primary 3-digit SIC code of the two firms are identical, and zero otherwise. The ratio is calculated as the number of identical 3-digit SIC code deals performed by adviser $j$, divided by the total number of deals for adviser $j$. More prestigious advisers have more experience and greater resources available to them, so it is anticipated that they will be able to complete more complex takeovers. Since the SIC compatibility ratio is equal to one if the deals are all simple, then the relationship between the ratio and the level of prestige is expected to be inverse. Thus a negative coefficient is anticipated.

The cross-sectional market share model above is developed to highlight what bidders consider important. Our approach is somewhat unique as it is annualised for each adviser. The independent variables are therefore aggregates of the particular attributes of the deals performed during the year. The league table is supposed to rank advisers based on perceived quality levels. If other deal attributes are overlooked, then the league table is capturing the wrong quality measure and needs improvement. The model should also help unlock how an adviser develops and retains its reputational capital (rank).

\section{G Summary}

The four data sources used in the three models have been developed to test the six hypotheses set out in Section III. The adviser used model specifically targets $\mathrm{H}_{1}$ (transaction cost hypothesis) and $\mathrm{H}_{2}$ (information asymmetry hypothesis), and aims to examine the externally observable factors that make a bidder choose to attempt a takeover over with or without an adviser. Using a reduced sample of 247 , the adviser choice model tests $\mathrm{H}_{3}$ (bargaining power hypothesis). That is, are higher ranked advisers associated 
with "good" deals? The unique annualised data used in the market share model examines $\mathrm{H}_{4}, \mathrm{H}_{5}$, (superior deal hypotheses) and $\mathrm{H}_{6}$ (deal completion hypothesis). The model is designed to determine if the league table is a good measure of adviser quality. The next Section discusses descriptive statistics, as well as the results obtained from the above models.

\section{Results}

\section{A Introduction}

The following results relate to descriptive statistics for the main sample, as well as the three models, the adviser used model, the adviser choice model, and the market share model. This is followed by a sensitivity analysis that examines the impact of other ranking methods on the hypotheses developed in Section III. The Section concludes with a suggestion for a new wealth ranking measure.

\section{B Descriptive Statistics}

Figure 1 shows the variation in volume of deals over time, and the relative distribution of the volume between takeovers with and without advisers. The figure is based on data from SDC Platinum and covers a larger sample than that used in the regression models of this paper. An examination of Figure 1 indicates several salient trends. The total market for takeovers experienced a slump during the period 1989 until 1994, after which the volume of takeovers grew very rapidly. Another observation from Figure 1 is that although there appears to be a core volume of deals performed every year without an adviser, the greatest growth has occurred in the part of the market using an adviser. This could be due to the advisers more actively suggesting deals to potential bidders. The data in Figure 1 highlight a shift in the proportion of deals using an adviser around the year 1994/5. The proportion of takeovers performed without an adviser appears to have experienced a permanent downward shift, from around 40 percent prior to 1994 to slightly less than 20 percent from 199526.

Descriptive statistics in Table 1 are based on the main dataset of 801 individual takeovers. There were 401 takeovers where no advisers were utilised, and 400 deals where at least one adviser was involved. There was a greater use of target advisers (328) relative to bidder advisers (247). This suggests targets either did not want to be taken over (and employed advisers to help defend against unwelcome bids), or were more anxious to ensure a "good" outcome was achieved for their shareholders.

It is also evident in Table 1 that most of the takeovers in the sample were performed in the latter part of the period. The last three years account for $60.8 \%$ of the sample. There is only one year (1991) where the percentage of bidder advised deals (26.19\%) exceeds the percentage of target advised deals (21.43\%).

\footnotetext{
${ }^{26}$ This may also be a reflection of the database, as SDC confirmed the database was more extensive after 1995.
} 
However, when the proportion of the total value of deals completed with the help of an adviser is compared with the proportion of volume of deals assisted by advisers in Figure 1, it becomes evident that the deals performed by advisers are large. In 1998, 42.18\% of takeovers in the sample used an adviser, yet Figure 1 indicates the value of deals with an adviser in 1998 was more than $80 \%$.

Table 2 gives general statistics for the full sample, for takeovers without an adviser, and for takeovers with a bidder adviser, and the breakdown of the prestige level of those advisers. Some interesting differences become evident once the full sample is partitioned. If a deal uses an adviser and the deal is completed, then the median time it takes to complete the deal (86 days) is almost three times as long when compared to completed takeovers performed without an adviser (31 days). The shorter time taken by deals with no advisers may be due to those deals being smaller, generally friendly and less complicated. Hence we cannot attribute the increase in deal completion time to the presence of advisers.

A greater number of takeovers are completed when the bidder uses an adviser (82.19\% versus $71.12 \%)$, thus while it may take longer to complete a deal with an adviser, the deal is more likely to be completed. It is interesting to note that second tier advisers $(73.08 \%)$ lag behind first $(89.87 \%)$ and third tier advisers $(83.33 \%)$ when it comes to completion rates. A possible reason for the higher completion rate in the third tier may be the presence of niche operators having superior skills in a narrow field.

The size of the takeover appears to help differentiate between the tiers; although this is not surprising given the tiers are based on volume of deals completed. The largest deals on average are performed by first tier advisers $(\$ A 100.1 \mathrm{~m})$, then second tier advisers $(\$ A 83.0 \mathrm{~m})$, third tier advisers $(\$ A 42.7 \mathrm{~m})$ and finally without (\$A10m) an adviser. Deals where no adviser is used involve bidders that are almost twice (1.99) the size of their targets. This indicates that if there is no adviser present, that the bidder does not dominate or intimidate its target. In fact the largest size discrepancy is in deals performed by first tier advisers (4.84) followed by second tier (4.51) and finally third tier (2.26).

Table 2 suggests a bidder is more likely to hire an adviser, as opposed to performing it without assistance, if: the bidder is listed ( $70.44 \%$ versus $57.94 \%$ ), has previous experience (59.52\% versus $43.84 \%$ ), does not pay cash $(64.71 \%$ versus $78.16 \%)$, and wants to perform a hostile takeover $(21.86 \%$ versus $4.51 \%)$. These findings suggest that advisers are able to perform certain types of takeovers better than bidders alone, and that method of payment is an important consideration when choosing to use an adviser. It is surprising to note that first tier advisers advise the greatest proportion of bidders with previous experience (63.29\%). This can be due to first tier advisers being involved with larger clients who can make several takeovers, or it might reflect some form of relationship banking. If the results reflect relationship banking, then a league 
table would be used to reaffirm the advisers continued ability to generate deal flow, and potentially also to draw in new clients.

It is very evident that hostile takeovers are generally performed using an adviser (21.86\% versus $4.51 \%$ ). The honour seems to befall second tier advisers $(28.21 \%)$ more often than first $(20.25 \%)$ or third tier (17.78\%) advisers. Perhaps this is a reflection of the current climate of large-scale mergers; hence first tier advisers are involved with the large mergers, leaving hostile takeovers to be performed mainly by the second tier advisers. Alternatively first tier advisers avoid hostile deals since they result in little value being added to the bidder. However, later results suggest this is not the case.

Deals using an adviser are more often well received by the market (34.41\%) than if no adviser is used (28.43\%). It should be noted that the majority of deals earn a negative return upon announcement. Bidders in takeovers involving second (43.59\%) and third (33.33\%) tier advisers more often capture more than $50 \%$ of the value generated than bidders with first tier advisers $(21.84 \%)$ and in deals where there is no adviser $(28.16 \%)$. Takeovers that are advised by first tier $(\$ \mathrm{~A} 0.70 \mathrm{~m})$ and second tier $(\$ \mathrm{~A} 2.76 \mathrm{~m})$ appear to create value for the bidder more than $50 \%$ of the time.

Table 3 reports the takeover related returns earned by ASX-listed sample firms around the bid announcement period. The returns are buy-and-hold abnormal returns for the event windows indicated in the first column. The returns that are statistically different from zero are in bold. The longer returns windows are those that are generally significant (day -60 to $0,-60$ to $+2,-30$ to +2 ). The returns over periods that exceed five days after the takeover (day 0 to $+5,0$ to +10 and 0 to completed/withdrawn) are not significantly different from zero in any of the breakdowns. An interesting observation is that none of the mean returns reported in the Table are significantly negative. Only bidders who used a second tier adviser earned significant positive abnormal returns around the time of the announcement. This suggests the second tier advisers may price their initial offer lower than others, such that the wealth retained by the bidder exceeds that which would otherwise have been earned. It should be noted that the returns are equally weighted, that is, a 5\% abnormal return on a $\$ 100$ million dollar market capitalisation carries the same weight as a 5\% abnormal return on a \$20 million firm. This may bias the results against first tier advisers. However, as first tier bidders are larger then the returns are expected to be relatively smaller. From this initial analysis it would appear that second tier advisers are the ones who add value, but appear not to receive the largest volume of deal flow.

\section{The Adviser Used Model}

Table 4 contains the results of seven regression estimates for the adviser used model. The model is estimated using a logistic regression; hence $\mathrm{R}^{2}$, s are not reported. The F-statistics and associated $\mathrm{p}$-values 
are all highly significant, suggesting a reasonable fit. Regression 1 is the full model. It contains both listed and unlisted firms, hence the use of the Bidder Listed dummy control. The model suggests a bidder is more likely to use an adviser if it is listed and intends to perform a large, hostile deal, for a diversified firm in the same primary industry, and using other forms of payment than just cash. The positive coefficient on Attitude, negative coefficient on the Cash and positive coefficient on Log (Transaction Size) variables support $\mathrm{H}_{1}$ (transaction cost hypothesis). The positive coefficient on Bidder Listed supports $\mathrm{H}_{2}$ (information asymmetry hypothesis), but the positive coefficient on Related Industry is inconsistent with both $\mathrm{H}_{1}$ (transaction cost hypothesis) and $\mathrm{H}_{2}$ (information asymmetry hypothesis).

When the number of observations used in the model is reduced, and the Market Reaction variable is substituted for the Bidder Listed variable (regression 2), then the F-statistic on the model becomes smaller, but remains highly significant. The sign and significance of the estimated coefficients for the independent variables remain similar to those in regression estimate one.

When the model is run for only unlisted bidders (regression 3), a number of previously significant factors become insignificant. It would appear that when the bidder is unlisted, then an adviser is more likely to be chosen if the deal is hostile, the transaction is large, and the target is diversified, however the method of payment and the relatedness of the target's industry are insignificant.

Bidders who have no prior experience (regression 4) are more likely to hire an adviser if the deal is hostile, requires non-cash finance, is large, and if the target is diversified with the target's core industry being similar to the bidder's. If the bidder does have previous experience (regression 5), then the only difference to inexperienced bidders is that the method of payment becomes insignificant. This suggests advisers are able to add value in ways other than by merely providing relatively easy access to capital. The Bidder Listed variable is insignificant in regression 4 and 5, so there is no support for $\mathrm{H}_{2}$ (information asymmetry hypothesis).

If there is a target adviser present (regression 6), then the important determinants again are: whether the deal is hostile, if the deal is large, whether the two firms operate in the same industry, and whether the target is diversified. This suggests that if the target uses an adviser, then the negotiation skills are more important than being able to provide easy access to capital. However, if no target adviser is present (regression 7) then the attitude, non-cash payment, the size of the deal, and the diversification of the target are important factors in choosing to use an adviser.

Overall the adviser used model supports $\mathrm{H}_{1}$ (transaction cost hypothesis) but finds limited support for $\mathrm{H}_{2}$ (information asymmetry hypothesis). The findings also suggest the adviser is not hired for a set range of 
reasons. It appears that the circumstances surrounding the takeover determine which skills the bidder is seeking from its adviser.

\section{The Adviser Choice Model}

The adviser choice model utilises the look-back ranking described in Section IV D.1 as well as the ex-ante cumulative ranking method set out in Section IV D.2. The look-back ranking was devised to build some degree of market memory into the measure of adviser quality.

The adviser choice model in Table 5 is estimated using a multi-logit regression. The model is estimated four times, once for each of the look-back measures, and once for the ex-ante cumulative ranking measure. The reason for the two intercepts is that there are three unique values the dependent variable takes on; hence the estimation is performed in three-dimensional space, rather than the two-dimensional space of standard logit.

For all four models the F-statistic is insignificant, which suggests any inferences drawn from the coefficients of the model must be interpreted with caution. The fact that Market Reaction is not significant means there is no support for $\mathrm{H}_{3}$ (bargaining power hypothesis). The only significant variables are Attitude and Cash. The positive coefficient on Attitude suggests less prestigious advisers are more often associated with hostile takeovers. The negative coefficient on the Cash variable suggests lower ranked advisers perform deals with more complicated financing, and perhaps that higher ranked advisers are able to more often raise the required debt finance for its bidder client. The lack of significance in all four models suggest the ranking on the league table is not a good indication of the attributes of an adviser's ability or quality that we would expect to be relevant to bidders. An alternative explanation is that the relevant attributes have been measured with too much error for the results to be significant.

\section{E The Market Share Model}

The market share model is estimated using two different definitions of market share. In one measure the denominator is the total volume of deals in the market, in the other measure the denominator is the total volume of advised deals i.e., a subset of the total market.

The results in Table 6 suggest the method used to rank the advisers (i.e., market share) is not an indicator of other aspects of quality. The only variable that is significant is last year's market share. This suggests advisers are more or less entrenched in their position. It also indicates that last year's league table is a good proxy for this years market share i.e., a good marketing tool. However, it is a marketing tool that does not indicate anything about quality. The sign on the accumulated wealth gain, and the ability to complete are in the wrong direction, albeit they are not significant. The lack of significance means there is no support 
for hypotheses $\mathrm{H}_{4}, \mathrm{H}_{5}$, (superior deal hypotheses) or $\mathrm{H}_{6}$ (deal completion hypothesis). This is despite the model having significant $\mathrm{F}$ values, and a reasonable $\mathrm{R}^{2}$.

\section{F Sensitivity Analysis}

The lack of significance in the adviser choice model and the market share model has lead to the following sensitivity analysis. Here we develop various other models to test the hypotheses of this study.

\section{F.1 - Adviser Choice Model with Rankings}

With the lack of significance observed in the original adviser choice model in Table 5, it was felt that the cut-off used to distinguish the tiers could cause incorrect conclusions. Accordingly, we test the sensitivity of the results to alternative definitions of the dependent variable. Instead of using the tier to which the adviser belongs, the actual adviser ranking is used as the dependent variable. The ranking used is the ex ante cumulative rank described in Section IV D.2. The ex ante cumulative rank was extended to be calculated over three bases: cumulation of the one year scores, the cumulation of a two-year rolling average, and the cumulation of a rolling three-year average.

Table 7 shows that changing from tiers to rankings improved the goodness of fit, with the F statistic becoming significant for all seven estimated models. For regression 1, the size of the deal is the most important variable when deciding on what prestige level of adviser to use. The negative coefficient indicates that higher ranked advisers perform larger deals. The marginally significant cash variable suggests the complicated financing deals are performed by lower ranked advisers, and that the higher ranked advisers have their clients pay in cash. Perhaps this reflects the strong capital backing of the more prestigious advisers, and the ability to provide debt finance to the bidder from within the "one-

When the rolling average is extended to two years (regression 2), size no longer is important, instead the significant variable becomes the log of previous acquisitions. The negative coefficient indicates the more deals performed previously, the more likely a bidder is to use a higher ranked adviser. Since size is insignificant there are two possible explanations for the significance of the previous acquisition variable. Firstly, repeat bidders realise the value an adviser can add, and may consider that higher ranked advisers do a better job. Secondly, higher ranked advisers may be better at suggesting acquisition partners, thereby establishing a good rapport with the bidder, leading to repeat business between the two. In the two and three year models the market reaction is also marginally significant. The positive coefficient suggests that deals advised by less prestigious firms are better received by the market. This is inconsistent with $\mathrm{H}_{3}$ (bargaining power hypothesis). Extending the rolling average to three years (regression 3) sees the method of financing become insignificant, and size becoming significant again. 
Regression 4 extends the window used to calculate the abnormal announcement return. The window is extended from day -1 to +1 to be an 11 -day window, i.e., -5 to +5 . The positive significant variable suggests less prestigious advisers work on takeovers that earn greater announcement period returns. Extending the window further (regression 5) to day -10 to +10 reaffirms the direction and significance of the return. The direction of the coefficient is opposite to that expected and rejects $\mathrm{H}_{3}$ (bargaining power hypothesis).

In regressions 6 and 7 various dummy variables are inserted to test the robustness of the findings. In regression 6, the log of previous acquisitions is removed, and in its place is a dummy to capture whether the bidder has any prior experience. The dummy is significant, the negative coefficient suggesting that more experienced bidders choose to use more prestigious advisers. The interesting observation is that size becomes a more significant variable, which may indicate Log (Previous Acquisitions) used in the previous estimates to a certain extent is capturing the size of the bidder. In regression 7 the new variable is a dichotomous variable equal to one if the bidder has a significant holding in the target, and zero otherwise. According to the Corporations Law s707, a person holding more than 5\% of the target is a significant shareholder. The lack of significance for the variable suggests the foothold the bidder has in the target is not a consideration for most bidders when choosing the prestige level of the adviser.

The sensitivity analysis indicates $\mathrm{H}_{3}$ (bargaining power hypothesis) is rejected, and that less prestigious advisers earn greater announcement period returns for their clients. Further, the longer the period of time used to rank advisers, the greater the number of adviser aspects highlighted by the rank. The results indicate the cumulative three-year rolling average is the best way to extend the period.

\section{F.2 Market Share Model with Rankings}

The models estimated in Table 6 failed to find support for $\mathrm{H}_{4}, \mathrm{H}_{5}$, (superior deal hypotheses) and $\mathrm{H}_{6}$ (deal completion hypothesis). This sensitivity analysis, like the one above, re-estimates the model using rankings. Firstly the ranking will be the simple look-back measures described in Section IV D.1, then the cumulative ex ante rankings will be used.

All models in Table 8 have significant $F$ statistics, and reasonable $\mathrm{R}^{2}$ s. For regression 1 the only variable that is significant is last year's market share. This is similar to the results of Table 6. Extending the lookback time frame to two (regression 2) and three years (regression 3) suggests the proportion of wealth obtained by the bidder is a significant determinant of current market share. The negative coefficient suggests higher ranked advisers capture greater rents on a consistent basis for the bidder. This provides some support for $\mathrm{H}_{5}$ (superior deal hypothesis). In addition to this, the compatibility of the bidder and the target also appears to be an important determinant. The negative coefficient indicates more prestigious 
advisers perform relatively more takeovers where the bidder and the target operate in the same primary industry. This may be an indicator of some degree of industry specialisation by higher ranked advisers. The coefficient also suggests that lower ranked advisers perform the more complicated deals. Perhaps this is because the higher ranked advisers have the ability to choose from a range of projects, therefore selecting those projects that are least likely to damage their reputational capital. Despite having to perform the more complicated deals, earlier results in Section V B show that second tier advisers are better at generating wealth for the bidder, hence this perhaps indicates that reputation is not built up by creating value, but by having a significant deal flow.

In the models that incorporate the cumulative ex ante ranking (regressions 4,5 , and 6), the $\mathrm{F}$ values increase. The ability to complete a deal becomes a significant variable. Surprisingly the coefficient is positive. This suggests lower ranked advisers are able to complete more of the deals attempted. This is opposite to what was expected by $\mathrm{H}_{6}$ (deal completion hypothesis). Last year's market share remains an important explanatory of this year's rank. The longer the period of time over which the cumulative ex ante measure is calculated, the less significant the SIC compatibility variable become. This suggests higher ranked advisers do not always have the luxury of picking the deals they are involved in. The cumulative ex ante rank based on the two and three-year rolling average is negatively associated with the proportion of wealth captured by the adviser. This supports $\mathrm{H}_{4}$ (superior deal hypothesis). The final variable that is significant across all three ex ante models is Attitude, which indicates advisers who perform hostile deals are more likely to be ranked higher. It is surprising to see that the SIC Compatibility changes sign when the ranking method changes. The significant positive variable in regression 4 suggests lower ranked advisers perform deals with less information asymmetry. This is opposite to what the "look-back" measures in regressions 1 to 3 found. However SIC compatibility is significant in only one of regressions 4, 5 and 6 , and thus any relationships are tenuous.

\section{F.3 Completion Rates Between the Tiers}

To determine if there is a significant difference in completion rates between the tiers, $\mathrm{t}$-tests were calculated ${ }^{27}$. Completion rates are not reported in tables, however, in summary, it appears that first tier advisers $(89.87 \%)$ have a higher completion rate than second tier advisers (73.08\%), and a higher completion rate than if no adviser were present (71.12\%). This supports $\mathrm{H}_{6}$ (deal completion hypothesis) i.e., higher ranked advisers complete more deals. However, there is no significant difference between the completion rates of first $(89.87 \%)$ and third tier $(83.33 \%)$ advisers. A possible reason for this that third tier advisers are hired for simpler deals that are easy to execute and complete.

\footnotetext{
${ }^{27}$ These results are not reported, but are available from the authors upon request.
} 
Second tier advisers (25.64\%) withdraw relatively more deals than first (10.13\%), and third tier (13.33\%) advisers, and there are more withdrawn second tier advised deals (25.64\%) than withdrawn deals involving no adviser $(12.27 \%)^{28}$. Thus second tier advisers appear to be lacking the ability to close out a deal. This provides some support for $\mathrm{H}_{6}$ (deal completion hypothesis), that is, bidders prefer first tier advisers because they are more capable of completing a deal. However, the number of observations in the Table are relatively low for some of the categories, hence the interpretations need to be qualified.

A second analysis of completion rates was performed after partitioning the sample into "good" deals, and ls are takeovers where the abnormal announcement day bidder return (day -1 to +1 ), is non-negative. The results are not reported in detail, however a pervasive observation is that deals performed with advisers have a higher completion rate for both "good" exception is that second tier advisers do not complete a significantly different number of "bad" deals than deals with no adviser do. The withdrawal rates for "good" deals do not differ significantly ${ }^{29}$.

First tier advisers (88.89\%) complete significantly more "bad" deals than second tier (68.63\%) advisers and more than if no adviser were present $(73.77 \%)$. This suggests first tier advisers provide a "no questions asked" type of service, which places deal completion above all else. This may indicate that the market considers deal completion a key quality. If management initiates a takeover and approaches an adviser, then if the adviser rejects the deal because it does not create value, then it is likely that the bidder will continue to go to advisers until one agrees to advise on it. First tier advisers may still protect their reputational capital by ensuring the deals they are involved in are more likely to complete.

Second tier (68.63\%) completion rates are below those of first (88.89\%) and third tier (82.76\%) advisers, and on par with deals performed without an adviser (73.77\%). As the results indicate second tier advisers $(29.41 \%)$ also withdraw more "bad" deals than first (11.11\%) and third tier (15.52\%), as well as deals with no advisers (11.76\%). Perhaps this indicates that second tier advisers are more concerned with ensuring value is created than ensuring the deal is completed.

\section{F.4 Capturing Wealth Between the Tiers}

To explore the area of wealth creation further an analysis of the proportion of wealth captured was performed. The sample was partitioned into tiers, and also into two groups. In one group the overall outcome of the deal was wealth creation, for the other group overall wealth was destroyed. Wealth is defined as the change in market capitalisation of the bidder, divided by the absolute value of the sum of the

\footnotetext{
${ }^{28}$ It is possible that deals involving no advisers may underreport withdrawal rates. If this is the case, then the percentage is also overstated.

${ }^{29}$ The analysis was repeated using a window of -5 to +5 to indicate whether a deal was considered to be "good" or $\mathrm{s}$ were obtained.
} 
change in market capitalisation of the bidder and the change in market capitalisation of the target. Change in market capitalisation is adjusted for index movements and is measured from the day of announcement until the day of completion or withdrawal.

The results in Table 9 suggest that first tier advisers do not perform a "superior" deal. That is, second tier advisers capture more of the wealth for the bidder in takeovers where wealth is created than first tier advisers (75.34\% compared with $34.99 \%$ ), and first tier advisers do not generate significantly more wealth creation than third tier advisers (11.56\%), or deals without an adviser (-6.20\%). This supports Rau (1999). Second tier advisers (75.34\%) capture significantly more wealth than third tier advisers $(11.56 \%)$. In takeovers where overall wealth is destroyed, the difference in wealth captured is not significantly different, except that first tier advisers (-137.71\%) destroy more bidder wealth than takeovers performed without an adviser (-69.40\%). Although there are significant differences in the "withdrawn" column, the lack of observations do not allow for meaningful interpretation.

When wealth is created it appears that the gains are divided between the bidder and the target. Second tier advisers appear to be able to capture a majority of the wealth for their bidders, as the mean wealth captured in a completed wealth creating deal is $75.34 \%$ i.e., for every $\$ A 100$ wealth created in the takeover, the bidder receives $\$ A 75.34$. This is the only figure that exceeds $50 \%$. For takeovers where wealth is destroyed it is evident that the bidder is left with the bulk of the losses. The smallest loss is made by deals performed without advisers, where the bidder captures $69.40 \%$ of the loss. For wealth destroying takeovers that involve an adviser, any gains are on average captured by the target. A percentage that exceeds $100 \%$ in the "wealth destroyed" columns indicates that the bidder's share price decreased, and that wealth was transferred to the target. The $137.71 \%$ loss experienced by bidders who use second tier advisers indicates for every $\$ 37.71$ increase in wealth by the target, the bidder lost $\$ 137.71$. The fact that the loss is greater for second and third tier advisers suggests they are not able to limit the losses to the same extent a first tier adviser can, however the differences are not significant.

Overall there is some weak support for second tier advisers being able to capture slightly more value for the bidder. However if the overall deal wealth is negative, then second tier advisers appear unable to reduce the losses to the same extent as first tier advisers and others are able. This final observation is not, however, significant. These results indicate the ranking of advisers on league tables does not indicate the underlying quality of the advisers, thus no support exists for $\mathrm{H}_{5}$ (superior deal hypothesis).

\section{$G$ Wealth Creation Ranking}

Given the results above, it appears that the SDC league table in its current form is not consistently capturing aspects of quality other than volume and perhaps completion rate. Managers represent 
shareholders, and should therefore strive to add value to the company, for this reason it may be more appropriate to rank advisers on their ability to capture wealth for the bidder.

\section{G.1 Calculation of the Wealth Creation Ranking}

With the wealth measure below, the focus is on bidders, as targets should always increase in wealth ${ }^{30}$. The wealth measure developed by this paper is:

$$
\text { Wealth Creation Score }=\frac{\sum \text { BidderWealthGain } \frac{1}{\# \text { Advisers }}}{\sum \text { DealValue } \frac{1}{\# \text { Advisers }}}
$$

The measure is the division of the wealth added to the bidder, divided by the number of advisers working on a given deal. Wealth is measured as the change in market capitalisation of the bidder from the time the bid is announced, until the takeover is completed, or withdrawn. The division by the number of advisers in each deal is done such that the gains are shared between the advisers, and so that a $\$ 10$ million gain on a deal performed by one adviser is given twice the value of a $\$ 10$ million gain on a deal performed with two advisers. The numerator is then summed before being divided by the weighted value of all deals the adviser has participated in.

The denominator, like the numerator, is a weighted total of all deals in which the adviser has been involved. Like the numerator, the denominator is summed prior to division, if this were not done, then the weighting would be superfluous, and the measure would simply become a summation of averages.

The above wealth creation scores are calculated on an annual basis for each adviser, after which the advisers' scores are ranked from highest to lowest.

\section{G.2 Discussion of the Measure}

The measure approaches the ranking procedure from a different perspective than the current league table. In order to rank higher on the wealth league table the adviser has to participate in takeovers that create shareholder wealth. The focus has shifted from the number of deals, and the size of the deals. In shifting from these measures smaller advisers who work in niche markets can be recognised for doing a good job. Working in a particular segment of the takeover market does not handicap smaller advisers.

\footnotetext{
${ }^{30} \mathrm{~A}$ bid has to exceed market price otherwise there is no incentive for the target to sell.
} 
The measure thus has a number of benefits including being standardised, shifting the focus to shareholder wealth creation, and considering the completion risk and role an adviser has in the deal. However, there are also shortcomings in the measure.

Wealth creation is currently only observable for bidders that are listed. Although wealth is still created or destroyed in deals where the bidder is not listed, accurate measurement of this is almost impossible. By focusing only on listed bidders a number of deals will be left out of the measure ${ }^{31}$. In addition the measure does not consider the quality of work performed for targets. A potential extension to the measure would be to include the wealth created for targets it in the measure, such that the measure would represent the whole market and not just the market for bidder advisers.

\section{G.4 Testing the Wealth Creation Measure}

Substituting the lagged ranking into the market share model tests the wealth creation model. By lagging the wealth creation ranking $\mathrm{H}_{4}$ (superior deal hypothesis) and $\mathrm{H}_{6}$ (deal completion hypothesis) are tested. The market share model is estimated three times, once for each "look-back". For the 2- and 3-year "lookbacks", the lagged wealth rank is estimated over a two or three year periods, and lagged by two or three years. In order for the regressions to be estimated all variables have to be available. The reduction in sample size comes mainly from the fact that advisers have to be in the sample for both the year of the SDC ranking, and the previous year for the wealth creation ranking to be calculated.

The model estimates are shown in Table 10. In regression 1 the positive significant variable on the lagged wealth rank suggests, that advisers who add value to their clients, are rewarded the following year with an increase in deal flow i.e., a higher rank on the league table. This supports $\mathrm{H}_{4}$ (superior deal hypothesis) and differs from the findings of Rau (1999). This result is important, as it appears managers of bidders do consider their shareholders when choosing an adviser. That is, if an adviser is seen by the market to have added value to bidders then the current bidders are more likely to direct their deals towards more capable advisers.

When the measure is lagged two years, and compared to the two year rolling average market share, the wealth creation measure remains significant, but the model itself is not well specified. If the ranks are averaged over three years, again the model is not well specified, with a negative $R^{2}$, and an insignificant $F$ value.

\footnotetext{
${ }^{31}$ In the sample of 801 takeovers used in this paper, $60.7 \%$ of all bidders were listed. They represented $66.5 \%$ of the deal values (measured as the deal value net of debt).
} 
Although the results that the market appears to reward advisers who create value a number of caveats need to be considered. The sample size of the takeovers used to estimate the model is relatively small (between 32 and 49 takeovers). The fact that the goodness of fit of the model declines sharply also indicates the model may not be very well specified. In order to properly test this wealth measure a larger sample size would have to be used.

\section{Conclusion}

Using a sample of 801 Australian takeovers contained in SDC Platinum attempted between 1989 and 1998, this paper investigated the following three issues. What deal attributes motivate some bidders to engage advisers? What factors do bidders consider when choosing the prestige level of an adviser? Does capturing greater value for the bidder result in a greater market share?

The results suggest that the circumstance under which the deal is performed dictates the deal attributes sought by the bidder. If the bidder is listed, has previous experience, does not pay solely with cash and wants to perform a hostile takeover then it is more likely to use an adviser. The results supported $\mathrm{H}_{1}$ (transaction cost hypothesis), but not $\mathrm{H}_{2}$ (information asymmetry hypothesis). Further, if deals are performed using an adviser then it is more likely to be well received by the market. It should be noted that the majority of deals are still negatively received; suggesting wealth creation for bidders is not the main priority for advisers.

The adviser choice model found no support for $\mathrm{H}_{3}$ (bargaining power hypothesis). The four estimates of the model were not well specified; hence the inferences drawn from them should be interpreted with caution. The significant coefficients suggest that more prestigious advisers were not associated with hostile takeovers, but more prestigious advisers were associated with cash acquisitions. This suggests more prestigious advisers protect their reputational capital, and can provide relatively easy access to debt financing should its clients require it.

The market share model found no support for $\mathrm{H}_{4}, \mathrm{H}_{5}$ (superior deal hypotheses), or $\mathrm{H}_{6}$ (deal completion hypothesis). The lack of support for the superior deal hypothesis is consistent with Rau (1999), however the lack of support for the deal completion hypothesis is inconsistent with Rau (1999). Potentially the initial ranking method used in this paper may not be the ideal way to assess advisers' performance.

Further analysis does indicate higher ranked advisers do complete more deals than second tier advisers, but not third tier advisers. First tier advisers are also more likely to force a "bad" deal to completion. By changing the dependent variable from tiers to ranks the adviser choice model also highlights that the league table is not a good indicator of other quality attributes i.e., neither deal completion nor wealth 
creation were significant. The market share model with rankings reaffirmed this by finding that the most important determinant of this year's market share is last year's market share. The market share model also finds that less prestigious advisers work on deals that earn greater announcement returns, and are able to capture a greater amount of the wealth created in a takeover on a consistent basis. The conclusion from this Section of analysis suggests first tier advisers do not perform superior deals. When wealth is created then second tier advisers capture more than twice the wealth of first tier advisers. However, when overall wealth is destroyed there is little difference between the tiers.

The SDC produced league table is a key marketing tool used by advisers to generate future revenue. The way the league table is calculated may be parsimonious and easy to interpret, but it does not capture key quality aspects i.e., there is no regard to completion rates or shareholder wealth creation. Based on the above results it was concluded that a new wealth creating ranking measure needed to be developed. This paper proposes the wealth creation ranking method. The measure attempts to address some of the shortcomings of the existing league table. It is a standardised measure of the amount of wealth the bidder adviser assists in creating for bidder shareholders. It has the benefit of targeting desirable behaviour i.e., wealth creation. To date it has only been possible to estimate the wealth using listed bidders in the sample, and it relies on the market for an accurate assessment of the wealth created by the takeover. The results generated from the wealth creation league table indicate that advisers who generate wealth in the previous period are rewarded in the following one year and two year periods with an increase in deal flow. However, creating wealth last period does not mean the bidder becomes a first tier adviser the following year. It should be noted that the results of the wealth creation measure are encouraging but further verification is needed using a larger sample size. 


\section{References}

Akerlof, G. "The Market for 'Lemons': Quality Uncertainty and the Market Mechanism." Quarterly Journal of Economics, 84 (1970), 488-500.

Beatty, R., and J. Ritter. "Investment Banking, Reputation, and the Underpricing of Initial Public Offerings." Journal of Financial Economics, 15 (1986), 213-232.

Benston, G., and C. Smith. "A Transactions Costs Approach to the Theory of Financial Intermediation." The Journal of Finance, 31 (1976), 215-231.

Bowers, H., and R. Miller. "Choice of Investment Bankers and Shareholders' Wealth of Firms Involved in Acquisitions." Financial Management, 19 (1990), 34-44.

Carter, R., F. Dark, and A. Singh. "Underwriter Reputation, Initial Returns, and the Long-run Performance of IPO Stocks." The Journal of Finance, 53 (1998), 285-311.

Carter, R., and S. Manaster. "Initial Public Offerings and Underwriter Reputations." The Journal of Finance, 45 (1990), 1045-1068.

Chang, S. "Takeovers of Privately Held Targets, Methods of Payment, and Bidder Returns." The Journal of Finance, 53 (1998), 773-784.

Chemmanur, T., and P. Fulghieri. "Investment Bank Reputation, Information Production and Financial Intermediation." The Journal of Finance, 49 (1994), 57-79.

Eccles, R., K. Lanes, and T. Wilson. "Are You Paying too Much for That Acquisition?" Harvard Business Review, July-August (1999), 136-146.

Hayes, S. "Investment Banking: Power Structure in Flux." Harvard Business Review, March-April (1971), $136-152$.

Jarrell, G., J. Brickley, and J. Netter. "The Market for Corporate Control: The Empirical Evidence Since 1980.” Journal of Economic Perspectives, 2 (1987), 49-68.

Jensen, M., and W. Meckling. "Theory of the Firm: Managerial Behavior, Agency Costs and Ownership Structure." Journal of Financial Economics, 3 (1976), 305-360.

Johnson, J., and R. Miller. "Investment Bank Prestige and the Underpricing of Initial Public Offering." Financial Management, 17 (1998), 19-29.

Logue, D. "On the Pricing of Unseasoned Equity Issues: 1965-1969." Journal of Financial and Quantitative Analysis, 8 (1973), 91-103.

Loughran, T., and A. Vijh. "Do Long-term Shareholders Benefit from Corporate Acquisitions?" The Journal of Finance, 52 (1997), 1765-1790.

Maddala, G. "Limited Dependent and Qualitative Variables in Econometrics." Cambridge University Press: Oakleigh (1992).

Maher, P., and R. Cooper. “The New Bulge Bracket.” The Investment Dealers' Digest, 62 (1996), 14-25.

Martin, K. "The Method of Payment in Corporate Acquisitions, Investment Opportunities, and Management Ownership.” The Journal of Finance, 51 (1996), 1227-1246. 
McLaughlin, R. "Investment-Banking Contracts in Tender Offers: An Empirical Analysis." Journal of Financial Economics, 28 (1990), 209-232.

McLaughlin, R. "Does the Form of Compensation Matter?" Journal of Financial Economics, 32 (1992), 223-260.

Megginson, W., and K. Weiss. "Venture Capitalists Certification in Initial Public Offerings." The Journal of Finance, 46 (1991), 879-904.

Michel, A., I. Shaked, and Y. Lee. "An Evaluation of Investment Banker Acquisition Advice: The Shareholders' Perspective." Financial Management, 20 (1991), 40-49.

Nanda, V., and Y. Yun. "Reputation and Financial Intermediation: An Empirical Investigation of the Impact of IPO Mispricing on Underwriter Market Value." Journal of Financial Intermediation, 6 (1997), $39-63$.

Rau, P. "Investment Bank Market Share, Contingent Fee Payments, and the Performance of Acquiring Firms." Journal of Financial Economics, 56 (2000), 293-324.

Rau, P., and T. Vermaelen. "Glamour, Value and the Post-Acquisition Performance of Acquiring Firms." Journal of Financial Economics, 49 (1998), 223-253.

Riva, A. “The Bulge Racket.” Institutional Investor, 31 (1997), 37-39.

Rock, K. “Why New Issues Are Underpriced.” Journal of Financial Economics, 15 (1986), 187-212.

Roll, R. “The Hubris Hypothesis of Corporate Takeovers.” Journal of Business, 63 (1986), 197-216.

Servaes, H., and M. Zenner. "The Role of Investment Banks in Acquisitions." Review of Financial Studies, 9 (1996), 787-815.

Travlos, N. "Corporate Takeover Bids, Methods of Payment, and Bidding Firms' Stock Returns." The Journal of Finance, 42 (1987), 943-963.

White, H. "A Heteroscedasticity Consistent Covariance Matrix Estimator and a Direct Test of Heteroscedasticity.” Econometrica, 48 (1980), 817-818. 
Figure 1

Value of Deals With and Without Advisers

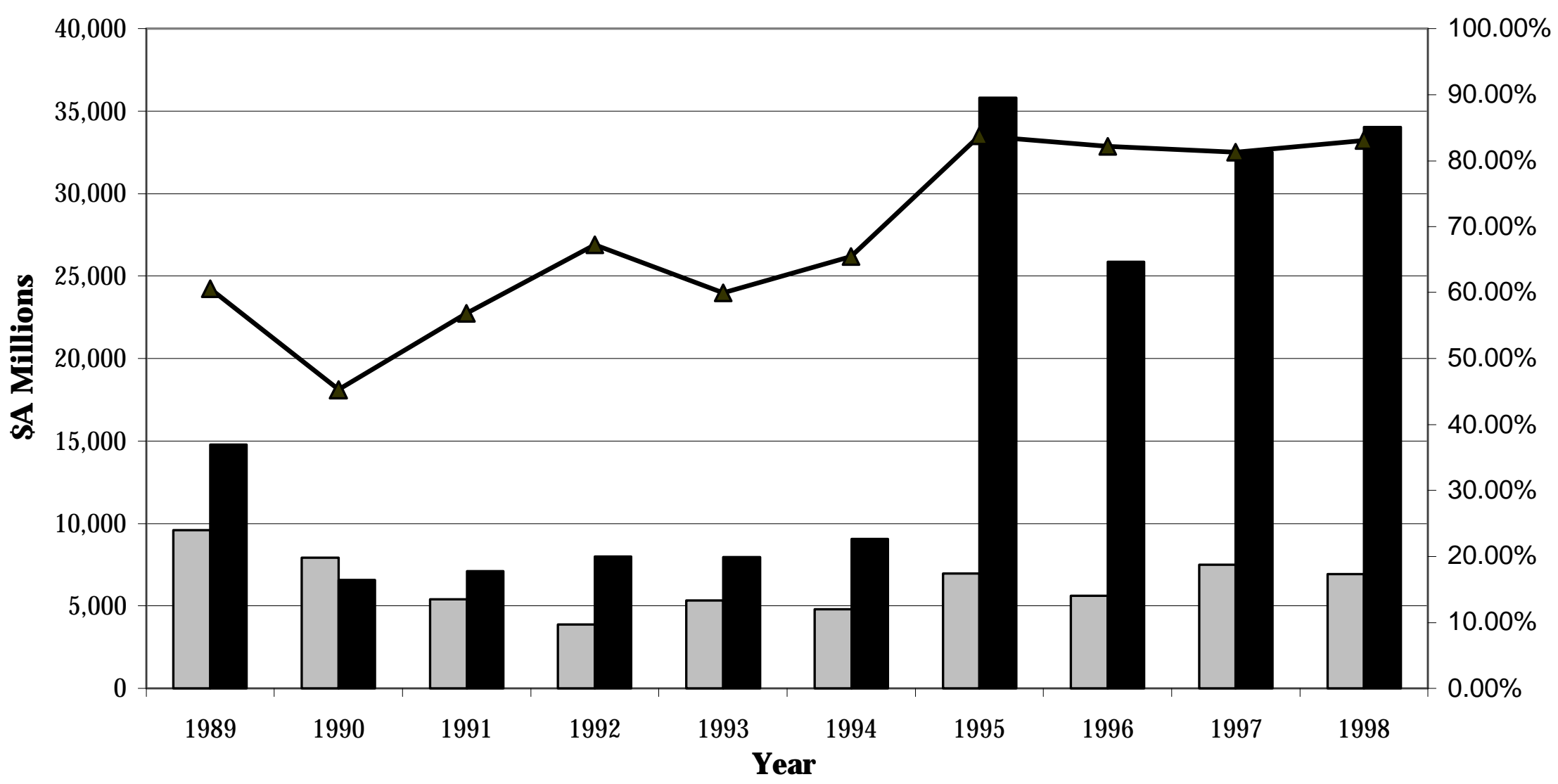

$\square$ Without Advisers $\square$ With Advisers $\triangle-$ Proportion with Advisers 
Table 1 Distribution of Advisers

Distribution of 801 Australian takeovers from 1989 through to 1998. The proportions in the All Takeovers column are the percentages relative to the total number of takeovers performed (801). The proportions in the "With an Adviser", "Without and Adviser", "With an Bidder Adviser", and "With a Target Adviser" columns, are the proportions that group of advisers represent for that year $\mathrm{i}$.

takeovers in with an adviser represented 44\% of the twenty five takeovers in 1989.

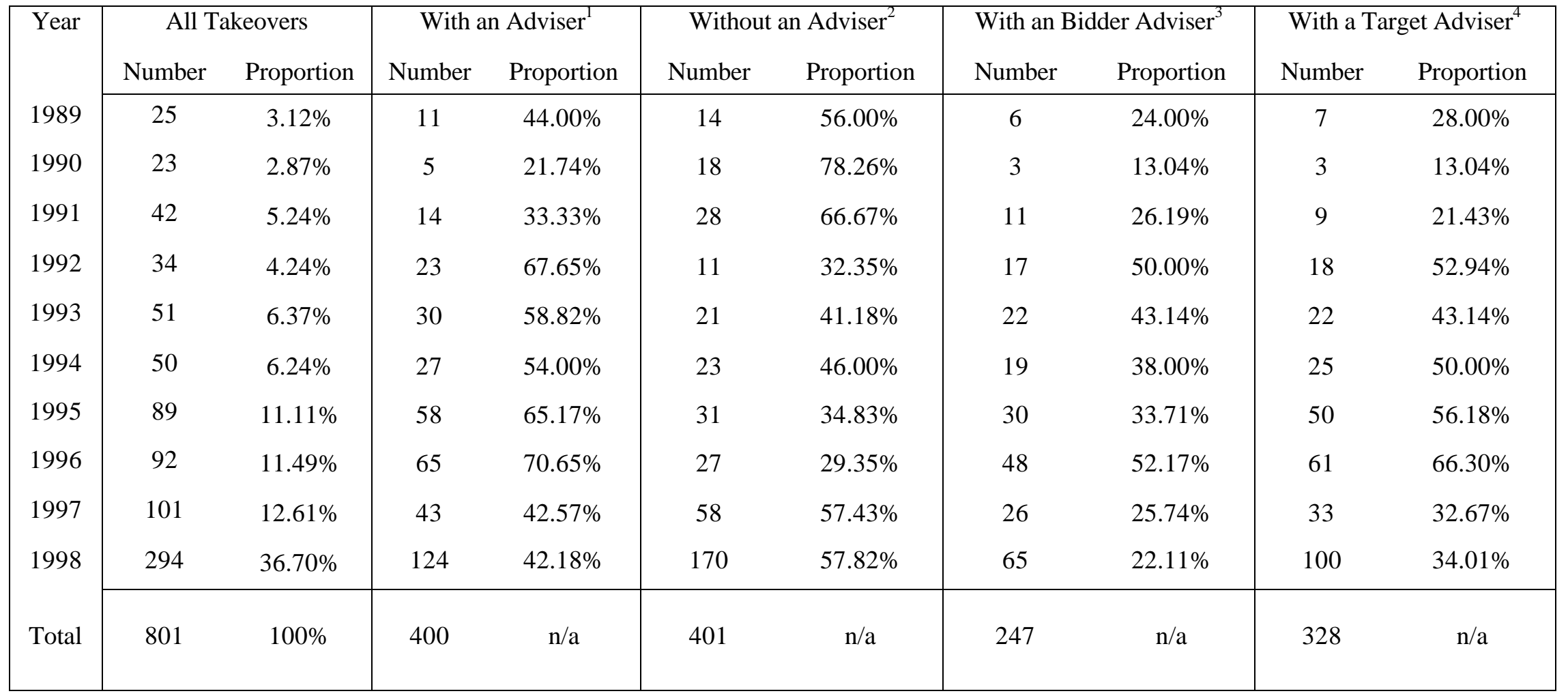

Percentages may not sum to 100 because of rounding.

1 - With an Adviser - the deal includes at least one adviser involved in the deal. The adviser can work for either the target or the Bidder.

2 - Without an Adviser - neither the Bidder nor the target employ the services of an adviser during the course of the takeover.

3 - With a Bidder Adviser - The deal is performed using at least one Bidder adviser.

4 - With a Target Adviser - The deal is performed using at least one target adviser. 
Table 2 Descriptive Statistics

Descriptive statistics for 801 Australian takeovers between January 1989 and December 1998.

\begin{tabular}{|c|c|c|c|c|c|c|}
\hline & $\begin{array}{c}\text { All } \\
\text { Takeovers }\end{array}$ & $\begin{array}{c}\text { No } \\
\text { Adviser }^{\mathrm{a}}\end{array}$ & $\begin{array}{l}\text { Bidder } \\
\text { Adviser }^{\mathrm{b}}\end{array}$ & $\begin{array}{l}\text { First Tier } \\
\text { Adviser }^{c}\end{array}$ & $\begin{array}{l}\text { Second } \\
\text { Tier } \\
\text { Adviser }^{\mathrm{c}}\end{array}$ & $\begin{array}{l}\text { Third Tier } \\
\text { Adviser }^{c}\end{array}$ \\
\hline Observations & 801 & 401 & 247 & 79 & 78 & 90 \\
\hline Median time to complete $^{\mathrm{d}}$ & 55 & 31 & 86 & 87 & 92 & 83 \\
\hline Median time to withdraw ${ }^{\mathrm{e}}$ & 85 & 79 & 90 & 84 & 86 & 102 \\
\hline Completion ratio $^{\mathrm{f}}$ & $74.53 \%$ & $71.12 \%$ & $82.19 \%$ & $89.87 \%$ & $73.08 \%$ & $83.33 \%$ \\
\hline Withdrawal ratio ${ }^{\mathrm{g}}$ & $13.48 \%$ & $12.27 \%$ & $16.19 \%$ & $10.13 \%$ & $25.64 \%$ & $13.33 \%$ \\
\hline $\begin{array}{l}\text { Median deal size (net of debt) \$A } \\
\text { millions }\end{array}$ & 21.3 & 10.0 & 72.0 & 100.1 & 83.0 & 42.7 \\
\hline Median relative Size ${ }^{\mathrm{h}}$ & 2.28 & 1.99 & 3.33 & 4.84 & 4.51 & 2.26 \\
\hline Proportion of bidders listed ${ }^{\mathrm{i}}$ & $61.80 \%$ & $57.94 \%$ & $70.44 \%$ & $72.15 \%$ & $66.67 \%$ & $70.00 \%$ \\
\hline Identical 3-digit SIC code & $35.83 \%$ & $33.57 \%$ & $40.89 \%$ & $41.77 \%$ & $42.31 \%$ & $38.89 \%$ \\
\hline Same ultimate parent $\mathrm{t}^{\mathrm{j}}$ & $8.99 \%$ & $9.03 \%$ & $8.91 \%$ & $10.12 \%$ & $8.97 \%$ & $7.78 \%$ \\
\hline Bidders with previous experience & $48.68 \%$ & $43.84 \%$ & $59.52 \%$ & $63.29 \%$ & $61.54 \%$ & $54.44 \%$ \\
\hline Hostile deals & $9.86 \%$ & $4.51 \%$ & $21.86 \%$ & $20.25 \%$ & $28.21 \%$ & $17.78 \%$ \\
\hline Pure cash acquisitions & $74.03 \%$ & $78.16 \%$ & $64.71 \%$ & $65.82 \%$ & $73.08 \%$ & $56.67 \%$ \\
\hline $\begin{array}{l}\text { Percent owned prior to } \\
\text { acquisition }\end{array}$ & $8.91 \%$ & $8.98 \%$ & $8.75 \%$ & $6.36 \%$ & $10.41 \%$ & $9.42 \%$ \\
\hline Percent owned after acquisition & $66.73 \%$ & $63.90 \%$ & $73.07 \%$ & $77.19 \%$ & $65.04 \%$ & $76.41 \%$ \\
\hline $\begin{array}{l}\text { Percent seeking to own after } \\
\text { acquisition }^{\mathrm{k}}\end{array}$ & $91.22 \%$ & $88.93 \%$ & $96.37 \%$ & $93.18 \%$ & $97.39 \%$ & $98.30 \%$ \\
\hline Market reacts positively ${ }^{1}$ & $31.46 \%$ & $28.43 \%$ & $34.41 \%$ & $32.91 \%$ & $32.05 \%$ & $37.78 \%$ \\
\hline Bidder captures $>50 \%$ of wealth ${ }^{\mathrm{m}}$ & $22.78 \%$ & $28.16 \%$ & $10.73 \%$ & $21.84 \%$ & $43.59 \%$ & $33.33 \%$ \\
\hline $\begin{array}{l}\text { Median value added to bidder } \\
\text { (\$A million) }\end{array}$ & -0.09 & -0.19 & -0.18 & 0.70 & 2.76 & -1.31 \\
\hline $\begin{array}{l}\text { Median value added to target (\$A } \\
\text { million) }\end{array}$ & 1.36 & 0.08 & 6.43 & 13.24 & 6.40 & 2.90 \\
\hline
\end{tabular}
(a) No Adviser - neither a target nor a bidder adviser participated in the deal.
(b) Bidder Adviser - at least one bidder adviser was participated in the deal.
(c) The descriptive statistics are for deals with at least one bidder adviser.
(d) Time to complete - the number of days from announcement until deal is complete.
(e) Time to withdraw - the number of days from announcement until deal is withdrawn.
(f) Completion ratio is calculated as: the number of deals completed, divided by the number of deals attempted.
(g) Withdrawal ratio is calculated as: the number of deals withdrawn, divided by the number of deals attempted (note there are 96 deals still "pending" in the sample, hence the completion and withdrawal ratios do not sum to 100\%).
(h) Relative size is Total Assets of the Bidder, divided by Total Assets of the Target.
(i) This is the percent of deals where the bidder is a publicly listed company.
(j) The percentage indicates the proportion of deals where the target and the bidder have the same ultimate parent.
(k) The stake the bidder would hold if all shares bid for were acquired. The percentage is the sum of the shares owned prior to the acquisition and the number of shares seeking to be purchased during the takeover.
(1) The percent of deals where the abnormal announcement day return (day -5 to +5$)$ is positive. Only listed bidders included.
(m) If the dollar return of the bidder exceeds the dollar return of the target then the bidder has captured more than $50 \%$ of wealth. Sample size reduced as only takeovers with listed bidder and target can be used. 
Table 3 Announcement Period Returns

The Table below presents the mean abnormal buy-and-hold returns earned by bidders for the periods indicated using the various level of advisers.

\begin{tabular}{|c|c|c|c|c|c|c|c|c|c|c|}
\hline \multirow{2}{*}{$\begin{array}{c}\text { Window } \\
\text { (Days relative to } \\
\text { announcement) }\end{array}$} & \multicolumn{2}{|c|}{ All Listed Bidders } & \multicolumn{2}{|c|}{ No Bidder Adviser } & \multicolumn{2}{|c|}{$\begin{array}{c}\text { Bidders Using First } \\
\text { Tier Advisers }\end{array}$} & \multicolumn{2}{|c|}{$\begin{array}{c}\text { Bidders Using Second } \\
\text { Tier Advisers }\end{array}$} & \multicolumn{2}{|c|}{$\begin{array}{r}\text { Bidders Using Third } \\
\text { Tier Advisers }\end{array}$} \\
\hline & $\begin{array}{c}\text { Return \% } \\
(\mathrm{n}=486 \\
)\end{array}$ & Student-t & $\begin{array}{c}\text { Return \% } \\
(\mathrm{n}=314 \\
)\end{array}$ & Student- $\mathrm{t}$ & $\begin{array}{l}\text { Return \% } \\
(\mathrm{n}=57)\end{array}$ & Student-t & $\begin{array}{l}\text { Return \% } \\
(\mathrm{n}=52)\end{array}$ & Student- $\mathrm{t}$ & $\begin{array}{c}\text { Return \% } \\
(\mathrm{n}=63)\end{array}$ & Student- $\mathrm{t}$ \\
\hline-60 to 0 & $4.007^{*: * 3 *}$ & 3.422 & 3.938 & 2.524 & $4.081^{*}$ & 1.746 & $3.972^{*}$ & 1.790 & 4.319 & 1.167 \\
\hline-60 to +2 & $4.421^{* * * *}$ & 3.643 & $4.302^{* * * *}$ & 2.626 & $4.443^{*}$ & 1.786 & $4.9366^{* * *}$ & 2.185 & 4.569 & 1.276 \\
\hline-30 to +2 & $2.900^{* * *}$ & 3.097 & $2.221^{*}$ & 1.882 & 3.843 & 1.325 & 3.037 & 1.539 & $5.322^{*}$ & 1.858 \\
\hline-10 to +10 & $1.216^{* *}$ & 2.186 & 0.578 & 0.854 & 1.137 & 0.625 & 1.929 & 1.478 & $3.881^{* *}$ & 2.187 \\
\hline-5 to +5 & $1.132^{* * *}$ & 2.244 & 0.587 & 0.967 & 1.114 & 0.793 & $2.793^{*}$ & 1.858 & 2.494 & 1.478 \\
\hline-2 to +2 & $0.695^{*}$ & 1.65 & 0.706 & 1.204 & 0.064 & 0.095 & $1.365^{*}$ & 1.850 & 0.657 & 0.574 \\
\hline-1 to +1 & 0.342 & 0.987 & 0.049 & 0.108 & -0.250 & -0.471 & $2.100^{* *}$ & 2.646 & 0.887 & 0.759 \\
\hline 0 to +2 & 0.465 & 0.207 & 0.398 & 0.763 & 0.276 & 0.451 & $1.023^{*}$ & 1.689 & 0.508 & 0.578 \\
\hline 0 to +5 & 0.387 & 0.929 & 0.110 & 0.206 & 1.140 & 0.887 & 0.726 & 0.979 & 0.807 & 0.646 \\
\hline 0 to +10 & 0.366 & 0.792 & -0.013 & -0.022 & 0.914 & 0.597 & 0.790 & 0.854 & 1.411 & 1.122 \\
\hline 0 to Completed & 1.408 & 0.817 & 2.191 & 0.871 & 0.303 & 0.078 & 4.671 & 1.396 & -3.490 & 1.013 \\
\hline 0 to Withdrawn & -0.501 & -0.293 & -2.319 & -1.331 & 8.976 & 0.879 & 2.246 & 0.701 & 7.313 & 0.780 \\
\hline
\end{tabular}

*** Significant at the $1 \%$ level

** $\quad$ Significant at the $5 \%$ level

* $\quad$ Significant at the $10 \%$ level 


\section{Table 4 Adviser Used Model}

The adviser used model below tests $\mathrm{H}_{1}$ and $\mathrm{H}_{2}$. It is estimated using a logit regression. The dependent variable in all cases is whether or not the bidder chose to use an adviser. The dummy is equal to one if the bidder used an adviser, and zero otherwise. Adviser Used $=\boldsymbol{\alpha}_{0}+\boldsymbol{\beta}_{\mathbf{1}} \mathbf{A t t i t u d e}+\boldsymbol{\beta}_{2}$ Cash + $\beta_{3} \log ($ Transaction Size $)+\beta_{4} \log ($ Previous Acquisitions $)+\beta_{5}$ Related Industry $+\beta_{6} \log (\#$ Target SICs $)+\beta_{7}$ Market Reaction $+\beta_{8}$ Bidder Listed $+\varepsilon$ (for further discussion on the variables see Section IV C.). Numbers in parentheses are standard errors. Significance levels are determined using one-tailed ttest cut-off values, as there are a priori expectations on the variables.

\begin{tabular}{|c|c|c|c|c|c|c|c|}
\hline & $\begin{array}{l}\text { Full Model - } \\
\text { no returns }\end{array}$ & $\begin{array}{l}\text { Full Model - } \\
\text { with returns }\end{array}$ & $\begin{array}{c}\text { Unlisted } \\
\text { Firms }\end{array}$ & $\begin{array}{c}\text { No Previous } \\
\text { Experience }\end{array}$ & $\begin{array}{c}\text { With } \\
\text { Previous } \\
\text { Experience }\end{array}$ & $\begin{array}{c}\text { Target } \\
\text { Adviser } \\
\text { Present }\end{array}$ & $\begin{array}{c}\text { No Target } \\
\text { Adviser } \\
\text { Present } \\
\end{array}$ \\
\hline Regression estimate & 1 & 2 & 3 & 4 & 5 & 6 & 7 \\
\hline Intercept & $\begin{array}{c}\mathbf{- 3 . 8 7 1}^{\text {**** }} \\
(0.428)\end{array}$ & $\begin{array}{c}\mathbf{- 3 . 5 4 3}^{\text {**** }} \\
(0.471)\end{array}$ & $\begin{array}{l}\mathbf{4 . 5 4 2}^{* * * *} \\
(0.840)\end{array}$ & $\begin{array}{c}\mathbf{- 4 . 0 2 1}^{* * * *} \\
(0.611)\end{array}$ & $\begin{array}{c}-3.490^{* * * *} \\
(0.623)\end{array}$ & $\begin{array}{c}\mathbf{- 3 . 1 3 9}^{* * * *} \\
(0.621)\end{array}$ & $\begin{array}{c}\mathbf{- 3 . 6 6 2}^{* * *} \\
(0.652)\end{array}$ \\
\hline \multicolumn{8}{|l|}{ Slope coefficients on: } \\
\hline Attitude & $\begin{array}{l}\mathbf{1 . 5 6 1}^{* * * *} \\
(0.281)\end{array}$ & $\begin{array}{l}\mathbf{0 . 9 9 9}^{* * * *} \\
(0.330)\end{array}$ & $\begin{array}{l}\mathbf{2 . 6 9 2}^{* * * *} \\
(0.540)\end{array}$ & $\begin{array}{l}\mathbf{1 . 6 7 1}^{* * * *} \\
(0.452)\end{array}$ & $\begin{array}{l}\mathbf{1 . 4 8 4}^{* * * *} \\
(0.361)\end{array}$ & $\begin{array}{l}\mathbf{1 . 1 7 0}^{* * *} \\
(0.349)\end{array}$ & $\begin{array}{l}\mathbf{1 . 2 7 8}^{* *} \\
(0.548)\end{array}$ \\
\hline Cash & $\begin{array}{l}-\mathbf{0 . 3 7 8}{ }^{* * *} \\
(0.204)\end{array}$ & $\begin{array}{c}\mathbf{- 0 . 4 1 9}^{* * *} \\
(0.227)\end{array}$ & $\begin{array}{l}-0.161 \\
(0.508)\end{array}$ & $\begin{array}{c}-\mathbf{0 . 6 1 7} \\
(0.325)\end{array}$ & $\begin{array}{l}-0.233 \\
(0.264)\end{array}$ & $\begin{array}{l}-0.092 \\
(0.280)\end{array}$ & $\begin{array}{l}\mathbf{- 0 . 4 8 0 *} \\
(0.326)\end{array}$ \\
\hline $\log ($ Transaction Size $)$ & $\begin{array}{l}\mathbf{0 . 4 8 7} \\
(0.054)\end{array}$ & $\begin{array}{l}\mathbf{0 . 5 0 2}^{* * * * *} \\
(0.070)\end{array}$ & $\begin{array}{l}\mathbf{0 . 5 1 8}^{* * * *} \\
(0.093)\end{array}$ & $\begin{array}{l}\mathbf{0 . 5 0 0}^{* * * *} \\
(0.076)\end{array}$ & $\begin{array}{l}\mathbf{0 . 4 7 3} \\
(0.077)\end{array}$ & $\begin{array}{l}\mathbf{0 . 4 8 0}^{* * * *} \\
(0.080)\end{array}$ & $\mathbf{0 . 2 9 6}^{* * * *}$ \\
\hline Log(Previous & 0.028 & 0.028 & 0.088 & (20) & 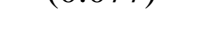 & 0.176 & -0.052 \\
\hline Acquisitions) & $(0.084)$ & $(0.100)$ & $(0.161)$ & & 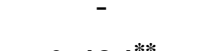 & $(0.126)$ & $(0.130)$ \\
\hline Related Industry & $\begin{array}{c}\mathbf{0 . 4 7 4}^{* * * *} \\
(0.184)\end{array}$ & $\begin{array}{l}\mathbf{0 . 6 6 5} \\
(0.2286)\end{array}$ & $\begin{array}{c}0.270 \\
(0.337)\end{array}$ & $\begin{array}{l}\mathbf{0 . 4 6 6}^{* * *} \\
(0.272)\end{array}$ & $\begin{array}{l}\mathbf{0 . 4 9 4}^{* * *} \\
(0.251)\end{array}$ & $\begin{array}{l}\mathbf{0 . 5 1 0 * *} \\
(0.262)\end{array}$ & $\begin{array}{c}0.030 \\
(0.301)\end{array}$ \\
\hline Log(\#Target SICs) & $\begin{array}{l}\mathbf{0 . 3 8 0}^{* * * *} \\
(0.151)\end{array}$ & $\begin{array}{l}\mathbf{0 . 3 7 7} \\
(0.187)\end{array}$ & $\begin{array}{l}\mathbf{0 . 5 4 4} 4^{* *} \\
(0.266)\end{array}$ & $\begin{array}{l}\mathbf{0 . 5 1 1}^{* * *} \\
(0.232)\end{array}$ & $\begin{array}{c}\mathbf{0 . 2 8 0} \\
(0.201)\end{array}$ & $\begin{array}{c}\text { 0.296* } \\
(0.217)\end{array}$ & $\begin{array}{l}\mathbf{0 . 4 5 0}^{*} \\
(0.236)\end{array}$ \\
\hline Market Reaction & - & $\begin{array}{l}\mathbf{0 . 0 3 7}^{* * * *} \\
(0.015)\end{array}$ & - & - & - & ( & - \\
\hline Bidder Listed & $\begin{array}{l}\mathbf{0 . 3 9 3}{ }^{\text {*** }} \\
(0.203)\end{array}$ & (0.015) & - & $\begin{array}{c}0.299 \\
(0.288)\end{array}$ & $\begin{array}{c}0.248 \\
(0.300) \\
\end{array}$ & $\begin{array}{l}-0.017 \\
(0.302)\end{array}$ & $\begin{array}{l}\mathbf{0 . 7 4 3}^{* *} \\
(0.317)\end{array}$ \\
\hline F-statistic & $191.635^{\text {**** }}$ & $112.091^{* * * * *}$ & $83.312^{* * * *}$ & $90.835^{* * * *}$ & $88.014^{* * * *}$ & $75.967^{\text {**** }}$ & $39.660^{* * *}$ \\
\hline Observations & 801 & 486 & 315 & 411 & 390 & 328 & 473 \\
\hline
\end{tabular}

*** $\quad$ Significant at the $1 \%$ level

** $\quad$ Significant at the $5 \%$ level

* $\quad$ Significant at the $10 \%$ level 


\section{Table 5 Adviser Choice Model}

The adviser choice model tests $\mathrm{H}_{3}$. The model is estimated using the following multi-logit regression. Tier $=\alpha+\beta_{1}$ Attitude $+\beta_{2}$ Cash Dummy + $\beta_{3} \log ($ Transaction Size $)+\beta_{4} \log ($ Previous Acq. $)+\beta_{5} \log (\#$ Target SIC Codes $)+\beta_{6}$ Market Reaction $+\beta_{7}$ Relative Size $+\beta_{8}$ Significant Bidder $+\varepsilon$. The dependent variable varies depending on the ranking method. The dependent variable is one if a first tier adviser is used, two is a second tier adviser, and three is a third tier adviser. The data used for this regression is based on a sample of 247 takeovers. This is the number of takeovers in the main sample where a bidder adviser has been involved. The regression is only run if all variables are available for a given takeover. Numbers in parentheses indicate the standard errors. There are a priori expectations for all the variables, thus one-tailed student-t values are used.

\begin{tabular}{|c|c|c|c|c|}
\hline Dependent Variable & $\begin{array}{c}1 \text { Year } \\
\text { Look-Back }\end{array}$ & $\begin{array}{c}\text { 2-Year } \\
\text { Look-Back }\end{array}$ & $\begin{array}{c}\text { 3-Year } \\
\text { Look-Back }\end{array}$ & $\begin{array}{c}\text { Ex-Ante } \\
\text { Cumulative }\end{array}$ \\
\hline Regression estimates & 1 & 2 & 3 & 4 \\
\hline Intercept 1 & $\begin{array}{l}\mathbf{2 . 2 5 6}^{*} \\
(1.519)\end{array}$ & $\begin{array}{c}1.756 \\
(1.529)\end{array}$ & $\begin{array}{l}\mathbf{2 . 6 6 6}^{*} \\
(1.568)\end{array}$ & $\begin{array}{c}1.187 \\
(1.510)\end{array}$ \\
\hline Intercept 2 & $\begin{array}{c}0.643 \\
(1.488)\end{array}$ & $\begin{array}{c}0.606 \\
(1.511)\end{array}$ & $\begin{array}{l}1.120 \\
(1.525)\end{array}$ & $\begin{array}{l}-0.089 \\
(1.501)\end{array}$ \\
\hline \multicolumn{5}{|l|}{ Slope coefficients } \\
\hline Attitude & $\begin{array}{c}0.723 \\
(0.619)\end{array}$ & $\begin{array}{l}\mathbf{0 . 9 0 3}^{*} \\
(0.634)\end{array}$ & $\begin{array}{l}\text { 1.401 } \\
(0.671)\end{array}$ & $\begin{array}{c}0.276 \\
(0.629)\end{array}$ \\
\hline Cash & $\begin{array}{l}-\mathbf{0 . 8 3 6} \\
(0.575)\end{array}$ & $\begin{array}{l}-0.741 \\
(0.585)\end{array}$ & $\begin{array}{l}-\mathbf{0 . 9 5 9} \\
(0.595)\end{array}$ & $\begin{array}{l}\mathbf{- 0 . 8 1 9} \\
(0.577)\end{array}$ \\
\hline Log (Transaction Size) & $\begin{array}{l}-0.190 \\
(0.227)\end{array}$ & $\begin{array}{l}-0.168 \\
(0.228)\end{array}$ & $\begin{array}{l}-0.287 \\
(0.232)\end{array}$ & $\begin{array}{l}-0.101 \\
(0.226)\end{array}$ \\
\hline Log (Previous Acquisitions) & $\begin{array}{c}0.124 \\
(0.249)\end{array}$ & $\begin{array}{l}-0.109 \\
(0.258)\end{array}$ & $\begin{array}{l}-0.191 \\
(0.270)\end{array}$ & $\begin{array}{l}-0.051 \\
(0.250)\end{array}$ \\
\hline Ln (\#Target SIC Codes) & $\begin{array}{l}-0.190 \\
(0.428)\end{array}$ & $\begin{array}{l}-0.138 \\
(0.444)\end{array}$ & $\begin{array}{l}-0.086 \\
(0.448)\end{array}$ & $\begin{array}{l}0.173 \\
(0.430)\end{array}$ \\
\hline Relative Size & $\begin{array}{l}-0.003 \\
(0.010)\end{array}$ & $\begin{array}{l}-0.001 \\
(0.010)\end{array}$ & $\begin{array}{l}-0.010 \\
(0.012)\end{array}$ & $\begin{array}{c}\mathbf{0 . 0 2 0} \\
(0.012)\end{array}$ \\
\hline Market Reaction & 0.017 & 0.039 & 0.028 & 0.013 \\
\hline & -0.054 & -0.036 & $\begin{array}{l}(0.04+) \\
-0.089\end{array}$ & $\begin{array}{c}(0.043) \\
0.376\end{array}$ \\
\hline Significant Bidder & $(0.615)$ & $(0.628)$ & $(0.638)$ & $(0.622)$ \\
\hline Observations & 56 & 55 & 54 & 56 \\
\hline F-statistic & 5.135 & 5.303 & 9.836 & 5.450 \\
\hline
\end{tabular}

*** Significant at the $1 \%$ level

** Significant at the $5 \%$ level

* Significant at the $10 \%$ level 


\section{Table 6 Market Share Model}

The market share model tests $\mathrm{H}_{4}, \mathrm{H}_{5}$, and $\mathrm{H}_{6}$, and is estimated using an OLS regression. Market Share $=\alpha_{0}+\beta_{0}$ Ability to Complete $+\beta_{1}$ Last Year's Market Share $+\beta_{2}$ Accumulated Wealth Gain $+\beta_{3}$ Merger/Tender $+\beta_{4}$ Proportion of Acquisitions $+\beta_{5}$ Average Deal Size $+\beta_{6}$ Time to Complete $+\beta_{7}$ Attitude $+\beta_{8}$ SIC Compatibility $+\varepsilon$. The dependent variable in all cases is the market share of the adviser. The data used for this regression is aggregated for each adviser on a per-anum basis. Numbers in parentheses are standard errors adjusted for heteroscedasticity (White, 1980). As there are a priori expectations for all the variables, the t-tests are one tailed.

\begin{tabular}{|c|c|c|c|c|c|c|}
\hline Dependent Variable & $\begin{array}{c}\text { Market } \\
\text { share for } \\
\text { advised } \\
\text { deals }\end{array}$ & $\begin{array}{c}\text { Advised } \\
\text { deals } \\
\text { standardised } \\
\text { wealth }\end{array}$ & $\begin{array}{c}\text { Advised } \\
\text { deals } \\
\text { wealth } \\
\text { proportio } \\
\text { n } \\
\end{array}$ & $\begin{array}{l}\text { Market } \\
\text { share for } \\
\text { all deals }\end{array}$ & $\begin{array}{c}\text { All deals } \\
\text { standardised } \\
\text { wealth }\end{array}$ & $\begin{array}{c}\text { All deals } \\
\text { wealth } \\
\text { proportio } \\
\text { n }\end{array}$ \\
\hline Regression estimates & 1 & 2 & 3 & 4 & 5 & 6 \\
\hline Intercept & $\begin{array}{l}\mathbf{7 . 6 7 6}^{* *} \\
(4.430)\end{array}$ & $\begin{array}{l}\mathbf{7 . 8 4 2}^{\text {** }} \\
(4.203)\end{array}$ & $\begin{array}{l}\mathbf{7 . 4 4 5}^{*} \\
(4.517)\end{array}$ & $\begin{array}{l}\text { 4.902 }^{*} \\
(3.302)\end{array}$ & $\begin{array}{l}\mathbf{4 . 5 7 9}^{*} \\
(3.098)\end{array}$ & $\begin{array}{l}\text { 4.779* }^{*} \\
(3.367)\end{array}$ \\
\hline \multicolumn{7}{|l|}{ Slope coefficients on: } \\
\hline Ability to complete & $\begin{array}{l}-1.896 \\
(2.763)\end{array}$ & $\begin{array}{l}-2.009 \\
(2.727)\end{array}$ & $\begin{array}{l}-1.816 \\
(2.733)\end{array}$ & $\begin{array}{l}-0.916 \\
(1.912)\end{array}$ & $\begin{array}{l}-0.901 \\
(1.892)\end{array}$ & $\begin{array}{c}-0.874 \\
(1.911)\end{array}$ \\
\hline Last year's market share & $\begin{array}{c}\mathbf{0 . 5 7 9}^{\text {********* }} \\
(0.118)\end{array}$ & $\begin{array}{c}\mathbf{0 . 6 0 9}^{* * * *} \\
(0.115)\end{array}$ & $\begin{array}{c}\mathbf{0 . 5 7 6} \text { **** }^{*} \\
(0.115)\end{array}$ & $\begin{array}{c}\mathbf{0 . 6 3 3}^{\text {***** }} \\
(0.133)\end{array}$ & $\begin{array}{c}\mathbf{0 . 6 6 2}^{* * * *} \\
(0.130)\end{array}$ & $\begin{array}{c}\mathbf{0 . 6 3 1}^{\text {****** }} \\
(0.131)\end{array}$ \\
\hline Accumulated wealth gain & $\begin{array}{l}-0.000 \\
(0.000)\end{array}$ & - & - & $\begin{array}{c}-0.000 \\
(0.000)\end{array}$ & - & - \\
\hline Bidder wealth per deal & - & $\begin{array}{l}-0.845 \\
(1.079)\end{array}$ & - & - & $\begin{array}{l}-0.414 \\
(0.834)\end{array}$ & - \\
\hline Proportion of wealth created & - & - & $\begin{array}{c}0.053 \\
(0.098)\end{array}$ & - & - & $\begin{array}{c}0.033 \\
(0.075)\end{array}$ \\
\hline Merger/Tender & $\begin{array}{c}0.600 \\
(2.191)\end{array}$ & $\begin{array}{c}0.711 \\
(2.033)\end{array}$ & $\begin{array}{c}0.678 \\
(2.193)\end{array}$ & $\begin{array}{c}-0.007 \\
(1.589)\end{array}$ & $\begin{array}{c}0.285 \\
(1.493)\end{array}$ & $\begin{array}{c}0.035 \\
(1.589)\end{array}$ \\
\hline Proportion of Acquisitions & $\begin{array}{l}-3.223 \\
(6.904)\end{array}$ & $\begin{array}{l}-2.747 \\
(6.527)\end{array}$ & $\begin{array}{l}-2.853 \\
(7.441)\end{array}$ & $\begin{array}{l}-2.152 \\
(5.164)\end{array}$ & $\begin{array}{l}-2.283 \\
(4.835)\end{array}$ & $\begin{array}{l}-1.924 \\
(5.583)\end{array}$ \\
\hline Average deal size & $\begin{array}{c}0.002 \\
(0.006)\end{array}$ & $\begin{array}{c}0.001 \\
(0.005)\end{array}$ & $\begin{array}{c}0.002 \\
(0.005)\end{array}$ & $\begin{array}{c}0.003 \\
(0.005)\end{array}$ & $\begin{array}{c}0.002 \\
(0.005)\end{array}$ & $\begin{array}{c}0.003 \\
(0.005)\end{array}$ \\
\hline Time to complete & $\begin{array}{c}-0.003 \\
(0.006)\end{array}$ & $\begin{array}{l}-0.001 \\
(0.006)\end{array}$ & $\begin{array}{l}-0.003 \\
(0.006)\end{array}$ & $\begin{array}{c}-0.001 \\
(0.005)\end{array}$ & $\begin{array}{c}0.001 \\
(0.005)\end{array}$ & $\begin{array}{c}-0.001 \\
(0.015)\end{array}$ \\
\hline Attitude & $\begin{array}{c}1.917 \\
(2.616)\end{array}$ & $\begin{array}{c}1.504 \\
(2.547)\end{array}$ & $\begin{array}{c}2.006 \\
(2.566)\end{array}$ & $\begin{array}{c}1.088 \\
(1.864)\end{array}$ & $\begin{array}{c}0.754 \\
(1.846)\end{array}$ & $\begin{array}{c}1.131 \\
(1.840)\end{array}$ \\
\hline SIC compatibility & $\begin{array}{l}-1.068 \\
(2.447)\end{array}$ & $\begin{array}{l}-0.810 \\
(2.428)\end{array}$ & $\begin{array}{l}-1.031 \\
(2.338)\end{array}$ & $\begin{array}{l}-0.174 \\
(1.837)\end{array}$ & $\begin{array}{c}0.250 \\
(1.842)\end{array}$ & $\begin{array}{c}-0.163 \\
(1.764)\end{array}$ \\
\hline Observations & 71 & 75 & 71 & 71 & 75 & 71 \\
\hline F-statistic & $4.132^{* * * *}$ & $5.050^{* * * *}$ & $4.144^{* * * *}$ & $5.189^{* * * *}$ & $6.108^{* * * *}$ & $5.197^{* * *}$ \\
\hline Adjusted $\mathrm{R}^{2}$ & 28.43 & 32.69 & 28.49 & 34.72 & 38.01 & 34.73 \\
\hline
\end{tabular}

$\begin{array}{ll}* * * & \text { Significant at the } 1 \% \text { level } \\ * * & \text { Significant at the } 5 \% \text { level } \\ * & \text { Significant at the } 10 \% \text { level }\end{array}$




\section{Table 7 Sensitivity on Adviser Choice Model}

The adviser choice model Rank $=\alpha+\beta_{1}$ Attitude $+\beta_{2}$ Cash Dummy $+\beta_{3} \log ($ Transaction Size $)+\beta_{4} \log ($ Previous Acq. $)+\beta_{5} \log (\#$ Target SIC Codes $)+$ $\beta_{6}$ Market Reaction $+\beta_{7}$ Sign. Bidder $+\varepsilon$ (discussed in Section IV E.) is estimated using OLS. It tests $\mathrm{H}_{3}$. The dependent variable is the ranking obtained from the Ex Ante Ranking Procedure discussed in Section IV D.2. The data used for this regression is based on a sample of 801 takeovers. The observations contained in the "Observations" column indicate the number of takeovers in each regression. Numbers in parentheses indicate the heteroscedasticity adjusted standard errors (White, 1980).

\begin{tabular}{|c|c|c|c|c|c|c|c|}
\hline Dependent Variable & $\begin{array}{c}\text { 1-Year } \\
\text { Ex Ante Rank }\end{array}$ & $\begin{array}{c}\text { 2-Year } \\
\text { Ex Ante Rank }\end{array}$ & $\begin{array}{c}\text { 3-Year } \\
\text { Ex Ante Rank }\end{array}$ & $\begin{array}{c}\text { 3-Year } \\
\text { Ex Ante Rank }\end{array}$ & $\begin{array}{c}\text { 3-Year } \\
\text { Ex Ante Rank }\end{array}$ & $\begin{array}{c}\text { 3-Year } \\
\text { Ex Ante Rank }\end{array}$ & $\begin{array}{c}\text { 3-Year } \\
\text { Ex Ante Rank }\end{array}$ \\
\hline Regression estimates & 1 & 2 & 3 & 4 & 5 & 6 & 7 \\
\hline Intercept & $\begin{array}{c}\mathbf{2 3 . 9 5 2}^{\text {***\% }} \\
(4.413)\end{array}$ & $\begin{array}{c}\mathbf{1 9 . 9 6 2}^{\text {****\%? }} \\
(3.473)\end{array}$ & $\begin{array}{c}\mathbf{1 7 . 4 8 5}^{\text {*:*** }} \\
(2.794)\end{array}$ & $\begin{array}{c}\mathbf{1 7 . 2 2 4}^{\text {*3*k }} \\
(2.764)\end{array}$ & $\begin{array}{c}\mathbf{1 6 . 9 6 0}^{\text {****** }} \\
(2.752)\end{array}$ & 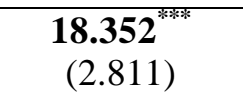 & $\begin{array}{c}\text { 16.929 }^{\text {**** }} \\
(2.729)\end{array}$ \\
\hline \multicolumn{8}{|l|}{ Slope coefficients on ${ }^{\mathrm{a}}$ : } \\
\hline $\begin{array}{l}\text { Attitude } \\
\text { Cash } \\
\text { Log (Transaction Size) } \\
\text { Log (Previous Acquisitions) }\end{array}$ & $\begin{array}{c}1.162 \\
(2.483) \\
\mathbf{- 2 . 7 8 2} \\
(1.875) \\
-\mathbf{1 . 3 9 3 *} \\
(0.646) \\
-1.106 \\
(0.851)\end{array}$ & $\begin{array}{c}1.353 \\
(2.036) \\
\mathbf{- 2 . 3 8 2} \\
(1.534) \\
-0.681 \\
(0.534) \\
\mathbf{- 1 . 4 7 4} \\
(0.726)\end{array}$ & $\begin{array}{c}0.824 \\
(1.646) \\
-1.547 \\
(1.270) \\
\mathbf{- 0 . 6 5 6}^{*} \\
(0.435) \\
\mathbf{- 1 . 3 2 6} \\
(0.610)\end{array}$ & $\begin{array}{c}0.981 \\
(1.627) \\
\mathbf{- 1 . 7 3 6} \\
(1.244) \\
\mathbf{- 0 . 6 1 6}^{*} \\
(0.438) \\
\mathbf{- 1 . 2 8 2}^{* *} \\
(0.599)\end{array}$ & $\begin{array}{c}1.056 \\
(1.605) \\
-1.394 \\
(1.272) \\
\mathbf{- 0 . 5 7 6}^{*} \\
(0.406) \\
\mathbf{- 1 . 3 2 0} * \\
(0.602)\end{array}$ & $\begin{array}{l}0.925 \\
(1.606) \\
-1.593 \\
(1.257) \\
-\mathbf{0 . 7 5 3} \\
(0.432) \\
-\end{array}$ & $\begin{array}{c}1.062 \\
(1.583) \\
-1.393 \\
(1.274) \\
\mathbf{- 0 . 5 7 2}^{*} \\
(0.442) \\
-\mathbf{1 . 3 2 7} \\
(0.601)\end{array}$ \\
\hline Previous acquisition dummy & - & - & - & - & - & $-2.999^{* *}$ & $(0.00)$ \\
\hline Log (\#Target SIC Codes) & $\begin{array}{c}0.268 \\
(1.540)\end{array}$ & $\begin{array}{c}-0.210 \\
(1.219)\end{array}$ & $\begin{array}{c}0.129 \\
(1.016)\end{array}$ & $\begin{array}{c}0.067 \\
(1.003)\end{array}$ & $\begin{array}{l}-0.008 \\
(0.991)\end{array}$ & $\begin{array}{l}-0.021 \\
(0.999)\end{array}$ & $\begin{array}{l}-0.010 \\
(0.995)\end{array}$ \\
\hline Market Reaction $(-1$ to +1$)$ & $\begin{array}{c}0.107 \\
(0.156)\end{array}$ & $\begin{array}{l}\mathbf{0 . 1 2 5}^{*} \\
(0.096)\end{array}$ & $\begin{array}{c}\mathbf{0 . 1 0 4} \\
(0.078)\end{array}$ & - & - & - & - \\
\hline Market Reaction $(-5$ to +5$)$ & - & - & - & $\begin{array}{l}\mathbf{0 . 0 9 0}^{* *} \\
(0.048)\end{array}$ & - & - & - \\
\hline Market Reaction $(-10$ to +10$)$ & - & - & - & - & $\begin{array}{l}\mathbf{0 . 0 9 0} \\
(0.044)\end{array}$ & $\begin{array}{l}\mathbf{0 . 0 8 8}^{* * *} \\
(0.043)\end{array}$ & $\begin{array}{l}\mathbf{0 . 0 9 0 * *} \\
(0.045)\end{array}$ \\
\hline Shares held prior to takeover & $\begin{array}{c}0.012 \\
(0.040)\end{array}$ & $\begin{array}{c}0.019 \\
(0.036)\end{array}$ & $\begin{array}{l}-0.007 \\
(0.029)\end{array}$ & $\begin{array}{l}-0.001 \\
(0.029)\end{array}$ & $\begin{array}{l}-0.001 \\
(0.028)\end{array}$ & $\begin{array}{l}-0.001 \\
(0.028)\end{array}$ & - \\
\hline Significant shareholder & - & - & - & - & - & - & $\begin{array}{c}0.064 \\
(1.324)\end{array}$ \\
\hline $\begin{array}{l}\text { Observations } \\
\text { F-statistic } \\
\text { Adjusted } \mathrm{R}^{2}\end{array}$ & $\begin{array}{c}171 \\
\mathbf{1 . 9 9 0}^{*} \\
3.89\end{array}$ & $\begin{array}{c}169 \\
2.236^{* * *} \\
4.87\end{array}$ & $\begin{array}{c}167 \\
2.280^{* *} \\
5.09\end{array}$ & $\begin{array}{c}167 \\
2.522^{* *} \\
6.00\end{array}$ & $\begin{array}{c}167 \\
\mathbf{2 . 5 9 4 ^ { * * }} \\
6.26\end{array}$ & $\begin{array}{c}167 \\
2.598^{* * *} \\
6.28\end{array}$ & $\begin{array}{c}167 \\
2.595^{* *} \\
6.27\end{array}$ \\
\hline
\end{tabular}

*** Significant at the $1 \%$ level

** Significant at the $5 \%$ level

* Significant at the $10 \%$ level 


\section{Table 8 Sensitivity on Market Share Model}

The market share model Rank $=\alpha_{0}+\beta_{0}$ Ability to Complete $+\beta_{1}$ Last Year's Market Share $+\beta_{2}$ Accumulated Wealth per Deal $+\beta_{3}$ Merger $/$ Tender + $\beta_{4}$ Proportion of Acquisitions $+\beta_{5}$ Average Deal Size $+\beta_{6}$ Time to Complete $+\beta_{7}$ Attitude $+\beta_{8}$ SIC Compatibility $+\varepsilon$ (described in Section IV F.) is estimated using an OLS regression. The regressions tests $\mathrm{H}_{4}$, and $\mathrm{H}_{5}$, and $\mathrm{H}_{6}$. The dependent variable in this sensitivity analysis is the rank attained by the adviser. The data used for this regression is aggregated for each adviser on a per-anum basis. Numbers in parentheses are heteroscedasticity adjusted standard errors (White, 1980). The Rank measure aggregates the deals done by the adviser over a 1, 2 or 3 year period. The ex Ante rank is based on the rank achieved by an adviser based on its points scored during the years it has been active. As there are a priori expectations for all the independent variables, the significance level cut-offs are calculated based on one-tailed t-tests.

\begin{tabular}{|c|c|c|c|c|c|c|}
\hline Dependent Variable & $\begin{array}{c}\text { Rank 1-Year } \\
\text { Look-Back }\end{array}$ & $\begin{array}{c}\text { Rank 2-Year } \\
\text { Look-Back }\end{array}$ & $\begin{array}{c}\text { Rank 3-Year } \\
\text { Look-Back }\end{array}$ & $\begin{array}{c}\text { Ex Ante Rank } \\
\text { 1-Yr Look-Back }\end{array}$ & $\begin{array}{c}\text { Ex Ante Rank } \\
\text { 2-Yr Look-Back }\end{array}$ & $\begin{array}{c}\text { Ex Ante Rank } \\
\text { 3-Yr Look-Back }\end{array}$ \\
\hline Regression estimates & 1 & 2 & 3 & 4 & 5 & 6 \\
\hline Intercept & $\begin{array}{c}\mathbf{2 1 . 5 2 5}^{* 3 . * *} \\
(5.559)\end{array}$ & $\begin{array}{c}\mathbf{2 7 . 2 3 5}^{* 3 * *} \\
(5.500)\end{array}$ & $\begin{array}{c}\mathbf{2 6 . 5 1 8}^{* 3 * * *} \\
(7.813)\end{array}$ & $\begin{array}{c}\mathbf{1 6 . 0 7 3}^{*+3 . *} \\
(5.413)\end{array}$ & $\begin{array}{c}\mathbf{1 6 . 4 9 7}^{\text {*3*** }} \\
(4.354)\end{array}$ & $\begin{array}{c}\mathbf{1 7 . 2 4 4}^{* 3 * * *} \\
(3.747)\end{array}$ \\
\hline \multicolumn{7}{|l|}{ Slope coefficients on ${ }^{\mathrm{a}}$ : } \\
\hline Ability to complete & $\begin{array}{l}-1.501 \\
(3.987)\end{array}$ & $\begin{array}{c}-2.754 \\
(4.148)\end{array}$ & $\begin{array}{c}-0.208 \\
(5.742)\end{array}$ & $\begin{array}{c}10.306 \\
(3.074)\end{array}$ & $\begin{array}{l}\mathbf{6 . 6 2 7} \\
(2.807)\end{array}$ & $\begin{array}{l}\mathbf{5 . 5 5 0} \\
(2.376)\end{array}$ \\
\hline Last year's market share & $\begin{array}{c}\mathbf{- 0 . 5 5 1}^{* * * * *} \\
(0.100)\end{array}$ & $\begin{array}{c}\mathbf{- 0 . 7 3 9}^{\text {******* }} \\
(0.130)\end{array}$ & $\begin{array}{c}\mathbf{- 0 . 9 5 3}^{* * * *} \\
(0.184)\end{array}$ & $\begin{array}{c}\mathbf{- 0 . 9 5 9}^{* * * *} \\
(0.093)\end{array}$ & $\begin{array}{c}\mathbf{- 0 . 8 6 9}^{* * * * *} \\
(0.088)\end{array}$ & $\begin{array}{c}\mathbf{- 0 . 9 5 4}^{* * * *} \\
(0.099)\end{array}$ \\
\hline Bidder wealth per deal & $\begin{array}{c}-0.794 \\
(1.256)\end{array}$ & $\begin{array}{c}\mathbf{- 3 . 0 8 5}^{* *} \\
(1.502)\end{array}$ & $\begin{array}{c}-\mathbf{2 . 6 2 4} \\
(1.501)\end{array}$ & $\begin{array}{l}-0.348 \\
(0.954)\end{array}$ & $\begin{array}{c}-\mathbf{2 . 3 9 7} \\
(0.892)\end{array}$ & $\begin{array}{c}\mathbf{- 1 . 3 6 7 * *}^{* * 3} \\
(0.626)\end{array}$ \\
\hline Merger/Tender & $\begin{array}{l}-1.406 \\
(2.480)\end{array}$ & $\begin{array}{l}-2.684 \\
(3.192)\end{array}$ & $\begin{array}{c}0.793 \\
(3.633)\end{array}$ & $\begin{array}{c}2.785 \\
(2.479)\end{array}$ & $\begin{array}{c}0.653 \\
(2.318)\end{array}$ & $\begin{array}{l}\mathbf{2 . 2 0 1}^{*} \\
(1.657)\end{array}$ \\
\hline Proportion of acquisitions & 2.766 & $\begin{array}{c}2.641 \\
(7738)\end{array}$ & $\begin{array}{l}-2.406 \\
(8.026)\end{array}$ & $\begin{array}{l}-1.698 \\
(6.993)\end{array}$ & 1.847 & $\begin{array}{l}-2.401 \\
(4.991)\end{array}$ \\
\hline & -0.007 & $\mathbf{- 0 . 0 0 9}$ & $\begin{array}{l}(8.020) \\
-0.007\end{array}$ & $\begin{array}{l}(0.993) \\
-0.004\end{array}$ & $\begin{array}{l}(0.335) \\
-0.004\end{array}$ & $\begin{array}{l}(4.991) \\
-0.001\end{array}$ \\
\hline Average deal size & $(0.007)$ & $(0.006)$ & $(0.008)$ & $(0.005)$ & $(0.003)$ & $(0.003)$ \\
\hline Time to complete & $\begin{array}{c}0.010 \\
(0.007)\end{array}$ & $\begin{array}{l}\mathbf{0 . 0 2 1} \\
(0.009)\end{array}$ & $\begin{array}{l}0.005 \\
(0.015)\end{array}$ & $\begin{array}{c}0.002 \\
(0.007)\end{array}$ & $\begin{array}{l}0.005 \\
(0.006)\end{array}$ & $\begin{array}{l}-0.010 \\
(0.008)\end{array}$ \\
\hline Attitude & -4.312 & -3.906 & -3.021 & $-8.222^{* * *}$ & $-4.947^{* * * *}$ & $-2.603^{*}$ \\
\hline Attitude & $(3.461)$ & $(4.431)$ & $(4.127)$ & $(3.449)$ & $(2.634)$ & $(1.785)$ \\
\hline SIC compatibility & $\begin{array}{l}-1.868 \\
(3.037)\end{array}$ & $\begin{array}{c}\mathbf{- 9 . 6 3 5} \\
(3.804)\end{array}$ & $\begin{array}{l}-\mathbf{- 7 . 1 2 2}^{*} \\
(4.300)\end{array}$ & $\begin{array}{l}\mathbf{5 . 8 1 5}^{* *} \\
(3.181)\end{array}$ & $\begin{array}{c}-1.396 \\
(2.462)\end{array}$ & $\begin{array}{l}-1.783 \\
(1.761)\end{array}$ \\
\hline Observations & 75 & 75 & 73 & 75 & 75 & 73 \\
\hline F-statistic & $4.154^{* * * *}$ & $3.327^{* * * *}$ & $2.945^{* * *}$ & $10.176^{* * * *}$ & $8.331^{* * * *}$ & $11.057^{* * *}$ \\
\hline Adjusted $\mathrm{R}^{2}$ & 27.46 & 21.83 & 19.34 & 52.41 & 46.80 & 55.36 \\
\hline
\end{tabular}

$\begin{array}{ll}* * * & \text { Significant at the } 1 \% \text { level } \\ * * & \text { Significant at the } 5 \% \text { level } \\ * & \text { Significant at the } 10 \% \text { level }\end{array}$




\section{Table 9 Wealth Captured by Various Adviser Tiers for Deals that Create or Destroy Wealth}

The Table assesses if there is a difference between the wealth retained between tiers, and between deals where wealth is created, or destroyed. The student t-statistic calculated for each paring indicates whether there is a significant difference between means of the two tiers. The classification method used is based on the 1-year lookback method. Wealth is created when the sum of the dollar gain to the bidder plus the dollar gain to the target exceeds zero. The sample is slightly reduced, as the wealth measure requires both the target and the bidder to be listed.

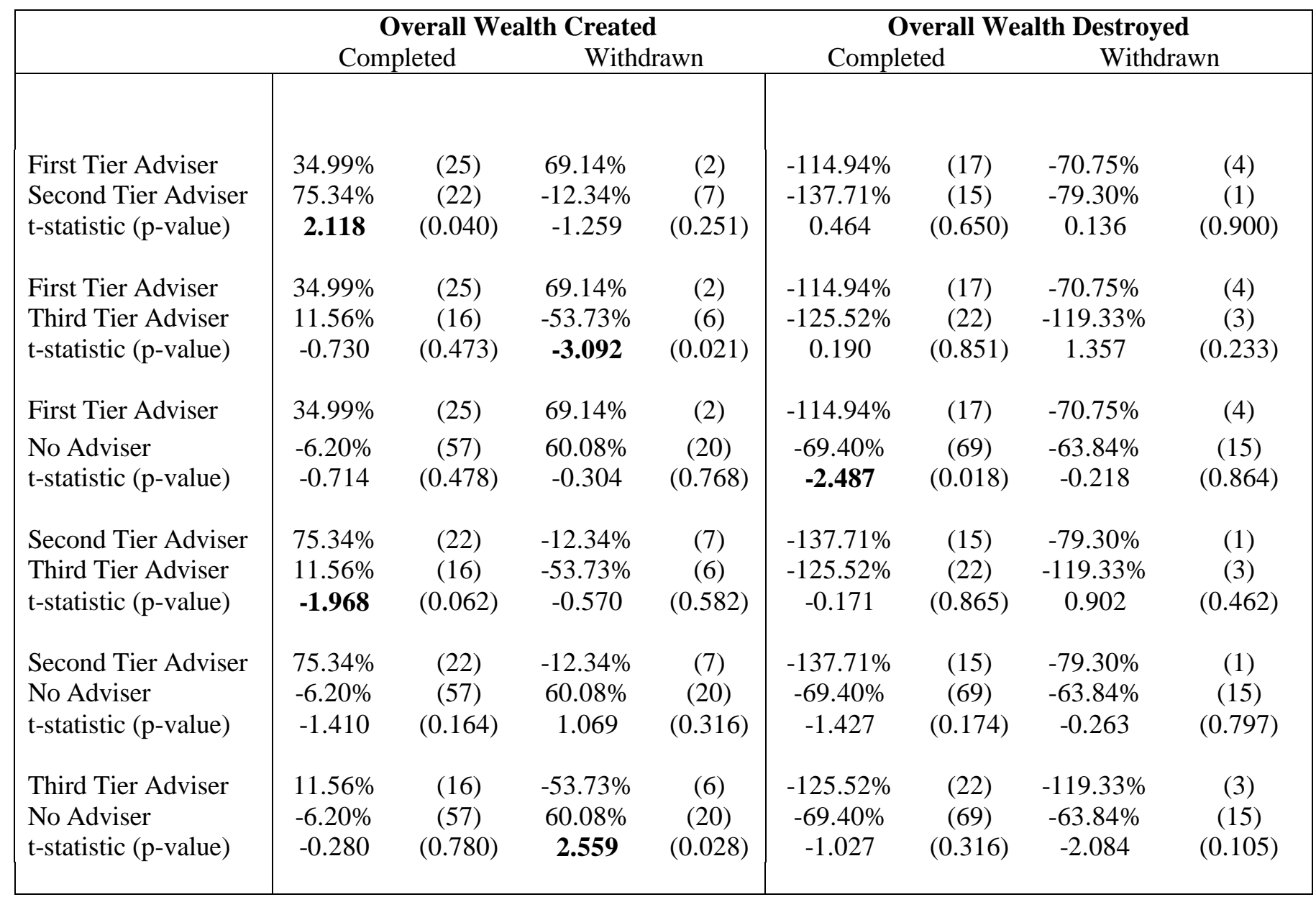




\section{Table 10 Market Share Model with Lagged Wealth Ranking}

The market share model Rank $=\alpha_{0}+\beta_{0}$ Ability to Complete $+\beta_{1}$ Lagged Wealth Rank + $\beta_{2}$ Merger/Tender $+\beta_{3}$ Proportion of Acquisitions $+\beta_{4}$ Average Deal Size $+\beta_{5}$ Time to Complete $+\beta_{6}$ Attitude $+\beta_{7}$ SIC Compatibility $+\varepsilon$ (described in Section IV F.) is estimated using an OLS regression. The dependent variable in all cases is the rank of the adviser (based on attempted deals), calculated over the past 1,2 or 3 years. The data used for this regression is aggregated for each adviser on a per-annum basis. Numbers in parentheses are heteroscedasticity adjusted standard errors (White, 1980). As there are a priori expectations for the coefficients one tailed cut-offs are used to test for significance.

\begin{tabular}{|c|c|c|c|}
\hline Dependent Variable & 1 Year Rank & 2 Year Rank & 3 Year Rank \\
\hline Regression estimates & 1 & 2 & 3 \\
\hline Intercept & $\begin{array}{c}\mathbf{1 9 . 2 7 5}^{* * * *} \\
(7.132)\end{array}$ & $\begin{array}{c}\mathbf{2 0 . 4 2 0}^{* * * *} \\
(7.743)\end{array}$ & $\begin{array}{c}12.020 \\
(10.646)\end{array}$ \\
\hline \multicolumn{4}{|l|}{ Slope coefficients on ${ }^{\mathrm{a}}$ : } \\
\hline Ability to complete & $\begin{array}{c}\mathbf{- 1 0 . 9 6 7}^{\text {**** }} \\
(4.091)\end{array}$ & $\begin{array}{l}-5.101 \\
(4.719)\end{array}$ & $\begin{array}{c}1.419 \\
(8.114)\end{array}$ \\
\hline Lagged wealth rank & $\begin{array}{c}\mathbf{0 . 7 2 0}^{* * * *} \\
(0.278)\end{array}$ & $\begin{array}{l}\mathbf{0 . 4 3 2}^{* *} \\
(0.244)\end{array}$ & $\begin{array}{c}0.039 \\
(0.180)\end{array}$ \\
\hline Merger/Tender & $\begin{array}{c}1.590 \\
(4.080)\end{array}$ & $\begin{array}{c}0.294 \\
(3.705)\end{array}$ & $\begin{array}{l}-0.015 \\
(5.141)\end{array}$ \\
\hline Proportion are Acquisitions & $\begin{array}{c}1.509 \\
(9.561)\end{array}$ & $\begin{array}{c}-\mathbf{1 9 . 2 9 0}^{* *} \\
(9.780)\end{array}$ & $\begin{array}{c}-0.477 \\
(11.002)\end{array}$ \\
\hline Average deal size & $\begin{array}{c}\mathbf{- 0 . 0 2 5}^{* * * *} \\
(0.007)\end{array}$ & $\begin{array}{c}-0.007 \\
(0.006)\end{array}$ & $\begin{array}{c}-0.004 \\
(0.006)\end{array}$ \\
\hline Time to complete & $\begin{array}{c}\mathbf{0 . 0 3 7}^{\text {**** }} \\
(0.012)\end{array}$ & $\begin{array}{l}\mathbf{0 . 0 2 2}^{* *} \\
(0.010)\end{array}$ & $\begin{array}{c}0.022 \\
(0.022)\end{array}$ \\
\hline Attitude & $\begin{array}{c}\mathbf{- 8 . 3 2 3}^{* * *} \\
(3.551)\end{array}$ & $\begin{array}{l}-2.316 \\
(3.736)\end{array}$ & $\begin{array}{l}-3.267 \\
(5.238)\end{array}$ \\
\hline SIC compatibility & $\begin{array}{c}\mathbf{- 1 2 . 1 1 8}^{* * * *} \\
(4.633)\end{array}$ & $\begin{array}{l}-4.570 \\
(4.371) \\
\end{array}$ & $\begin{array}{c}1.419 \\
(8.114)\end{array}$ \\
\hline Observations & 44 & 49 & 32 \\
\hline F-statistic & $3.192^{* * *}$ & 1.416 & 0.322 \\
\hline Adjusted $\mathrm{R}^{2}$ & 28.50 & 6.35 & -0.2043 \\
\hline
\end{tabular}

$\begin{array}{ll}* * * & \text { Significant at the } 1 \% \text { level } \\ * * & \text { Significant at the 5\% level } \\ * & \text { Significant at the } 10 \% \text { level }\end{array}$

(a) Ability to complete - total number of deals completed, divided by total number of deals attempted.

Lagged wealth rank - is the rank achieved by an adviser in the previous year after being ranked on the measure described in Section V G.1.

Merger/Tender - a proportion that divides the number of mergers and tenders attempted by the adviser, by the total number of deals attempted.

Proportion are acquisitions - the number times the adviser worked for bidders, divided by the sum of deals attempted for bidders and deals attempted for targets.

Average deal size, is the sum of the value of all deals attempted (net of debt) divided by the number of deals.

Time to complete, is the average time taken from announcement of the takeover until the deal is completed.

Attitude is the proportion of all deals attempted which have been hostile in nature.

SIC compatibility is the ratio of the number of times a deal has involved bidders and targets with the same 3-digit primary SIC code, divided by the number of deals attempted. 